Review

\title{
uPAR: An Essential Factor for Tumor Development
}

\author{
Tao Lv ${ }^{1,2 \llbracket \#, ~ Y i n g ~ Z h a o ~}{ }^{1 \#, ~ X i n n i ~ J i a n g ~}{ }^{3 \#}$, Hemei Yuan ${ }^{1}$, Haibo Wang ${ }^{1,2}$, Xuelin Cui ${ }^{1}$, Jiashun Xu1 ${ }^{1}$, Jingye \\ Zhao $^{1}$, Jianlin Wang ${ }^{\bowtie}$ \\ 1. College of Biological Resource and Food Engineering, Qujing Normal University, Qujing, Yunnan, China 655011. \\ 2. Key Laboratory of Yunnan Province Universities of the Diversity and Ecological Adaptive Evolution for Animals and Plants on YunGui Plateau, Qujing \\ Normal University, Qujing, China 655011. \\ 3. School of Biological Sciences and Technology, Chengdu Medical College, Chengdu, Sichuan, China 610500. \\ 4. College of Chemistry and Environmental Science, Qujing Normal University, Qujing, Yunnan, China 655011. \\ \#These authors contributed equally to this work. \\ $\triangle$ Corresponding authors: lvtao031@mail.qjnu.edu.cn; Tel.: +86-874-889-8627; Fax: +86-874-889-8627; E-mail: jlwang1984@163.com; Tel.: +86-874-896-5132; Fax: \\ $+86-874-896-5132$
}

(c) The author(s). This is an open access article distributed under the terms of the Creative Commons Attribution License (https://creativecommons.org/licenses/by/4.0/). See http://ivyspring.com/terms for full terms and conditions.

Received: 2021.05.03; Accepted: 2021.10.02; Published: 2021.10.17

\begin{abstract}
Tumorigenesis is closely related to the loss of control of many genes. Urokinase-type plasminogen activator receptor (uPAR), a glycolipid-anchored protein on the cell surface, is controlled by many factors in tumorigenesis and is expressed in many tumor tissues. In this review, we summarize the regulatory effects of the uPAR signaling pathway on processes and factors related to tumor progression, such as tumor cell proliferation, adhesion, metastasis, glycolysis, tumor microenvironment and angiogenesis. Overall, the evidence accumulated to date suggests that uPAR induction by tumor progression may be one of the most important factors affecting therapeutic efficacy. An improved understanding of the interactions between uPAR and its coreceptors in cancer will provide critical biomolecular information that may help to better predict the disease course and response to therapy.
\end{abstract}

Key words: uPAR, tumorigenesis, proliferation, adhesion, metastasis, cancer therapy

\section{Introduction}

Tumors are the result of uncontrolled proliferation of cells in different organs. Tumor development is a multistage process, that includes the generation of primary tumors, separation of tumors from primary sites, degradation of extracellular matrix (ECM), and distant metastasis of tumors. A variety of genes play important roles in the development of tumors [1-3], including the cell surface receptor urokinase-type plasminogen activator receptor (uPAR). uPAR is highly expressed in a variety of tumor cells, and a variety of signals regulated by UPAR play significant roles in tumor cell proliferation and metastasis, tumor-related glycolysis, the tumor microenvironment and angiogenesis [4-6]. Studies have found that some specific drugs and antibodies have unique inhibitory effects on uPAR. This review intends to deliver an overview of current knowledge about the role of UPAR in cancer progression and attempts to provide a theoretical basis for tumor therapy.

\section{Structural characteristics of uPAR}

uPAR, also known as CD-87, was discovered by Vassalli et al. in 1985 [7]. uPAR is a cysteine-rich glycosylated single-chain protein with a relative molecular weight of $50 \mathrm{kD}-60 \mathrm{kD}$ [8]. uPAR encodes a protein of 335 amino acids comprising 22 amino acids (secreted signal peptides) at the N-terminus and 30 amino acids at the C-terminus, which is bound to the cell membrane via a glycosyl phosphatidyl inositol (GPI) anchor [9] (Fig. 1A). As reported, uPAR consists of three domains ranging in size from 81 to 87 amino acids, namely D1, D2 and D3 [10], which are connected by short linker regions [11, 12] (Fig. 1B). The D1 block binds to urokinase-type plasminogen activator (uPA), the D3 region anchors uPAR to the membrane surface via a GPI, and the D2 sector joins the D1 and D3 sectors together. The N-terminus of the 
arginine-glycine-aspartic acid (RGD) or somatomedin-B (SMB) structure binds to the hydrophobic chamber of uPAR [13, 14] (Fig. 1B).

Transmembrane glycerophosphodiesterase GDE3, as a GPI-specific phospholipase C, cleaves and releases UPAR from the cell membrane surface to produce the soluble type of UPAR (suPAR) $[9,15,16]$. suPAR contains the ligand binding sites of UPAR and is present in plasma, urine, blood, serum and cerebrospinal fluid [17]. uPAR cleavage results in the hydrolysis of the specific SMB-binding site between D1 and D2 in the uPAR structure [18]. Consequently, there are three different structural forms of suPAR: the complete $\mathrm{D} 1+\mathrm{D} 2+\mathrm{D} 3$ structure, the D2+D3 structure and the free D1 fragment [11, 12, 19-21] (Fig. 1C).

\section{The uPA/uPAR system}

The uPA/uPAR system is composed of uPA, uPAR, plasminogen activator inhibitor-1 (PAI-1), endogenous plasminogen activator inhibitor-2 (PAI-2) and plasminogen [4, 15]. PAI-1 and PAI-2 exhibit inhibitory action on the uPA/uPAR system (Fig 1C). The trimer complex formed by the binding of uPA and UPAR with PAI-1 can be recognized by lipoprotein receptor-related protein and endocytosed into cells. The uPA system regulates the interaction between cells and the ECM through proteolytic cascade reaction and further regulates cell signal transduction [22]. As ligands of uPAR, uPA and vitronectin can simultaneously bind to UPAR at different binding sites $[20,23]$. uPA is a single-chain protein with a molecular weight of $54 \mathrm{kD}$ that contains an N-terminal domain with an EGF-like sequence, through which uPA can bind to the three domains of uPAR by forming a large hydrophobic cavity [24-26]. Vitronectin, a viscous glycoprotein with a molecular weight of $75 \mathrm{kD}$, is widely found in blood and ECM and interacts with different kinds of ligands $[27,28]$.

\section{The role of UPAR in tumors}

As early as 1991, Os-sutski et al. discovered that UPAR is closely related to cancer [29]. In recent years, with the help of positron emission tomography (PET) imaging, various studies have reported that the expression levels of UPAR in patients with breast cancer, prostate cancer, bladder cancer and colorectal cancer are significantly higher than those in normal tissues [30, 31]. Moreover, patients with a higher expression level of UPAR have a lower survival rate and poorer prognosis than those with lower expression [32]. Knocking out the UPAR gene in mice leads to G2/M arrest, thereby inhibiting cell proliferation [33]. In contrast, overexpression of the UPAR gene results in the promotion of tumor cell proliferation, migration, invasion and adhesion [4]. Therefore, uPAR plays an important role in tumorigenesis and development. This review mainly describes the expression of UPAR in tumors and the important roles of the UPAR signaling pathway in tumor cell proliferation, cell adhesion, metastasis, glycolysis, the tumor microenvironment and angiogenesis (Fig. 2).

\section{Expression of UPAR in cancer}

$U P A R$ expression is elevated during inflammation and tissue remodelling and in many human cancers [4], including prostate cancer [34-36], bladder cancer [37, 38], colon cancer [39], breast cancer [40, 41], melanoma [42], brain cancer [43], lung cancer [44], renal cell carcinoma [45], liver cancer [46, 47], gastric cancer [48, 49], ovarian cancer [50, 51], head and neck cancer [52], cervical cancer [53] and pancreatic cancer

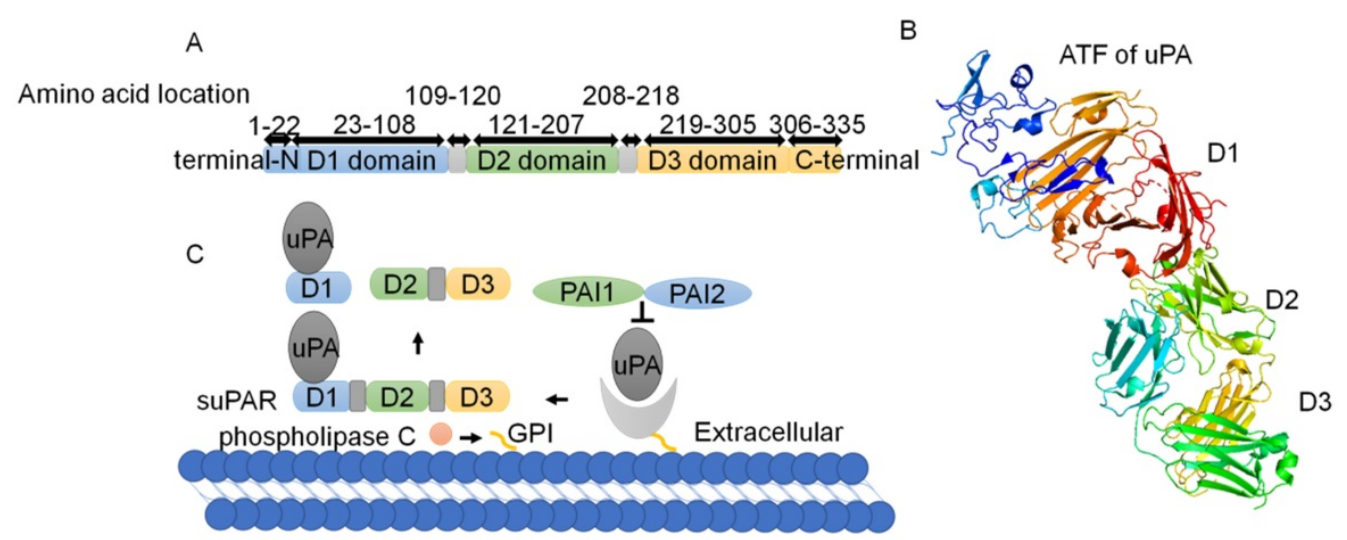

Figure 1. Two dimensional (2D) and three dimensional (3D) structures of uPAR. (A) uPAR encodes a protein of 335 amino acids comprising 22 amino acids (secreted signal peptides) at the $\mathrm{N}$-terminus and 30 amino acids at the C-terminus. uPAR consists of three domains ranging in size from 81 to 87 amino acids, namely, D1, D2 and D3, which are connected by short linker regions. (B) The 3D structure of uPAR, with domains colored as in part(Protein Data Bank identifier 3BT2). (C) PAI-1 and PAI-2 exhibit inhibitory action on the uPA/uPAR system. Phospholipase $C$ cleaves and releases uPAR from the cell membrane surface to suPAR, and uPAR cleavage results in hydrolysis of the specific SMB-binding site between D1 and D2 in the uPAR structure. Consequently, there are three different structural forms of suPAR: the complete D1+D2+D3 structure, the D2+D3 structure and the free D1 fragment. 
[54]. Sustained high expression of uPAR is associated with the growth and metastasis of cancer cells $[55,56]$. Moreover, uPA is also highly expressed in invasive tumors [57]. The uPA/uPAR interaction can promote the expression of oncogenes and cell proliferation, eventually leading to the development of tumors [58]. Knockout of the uPAR gene in tumor cells with the CRISPR/Cas9 system results in the inhibition of cell proliferation, migration and invasion [59]. A decrease in $\mathrm{UPAR}$ expression on the cell surface mitigates the development of hallmarks of cancer caused by PIK3CA and KRas mutations in colorectal cancer [60]. By interacting with uPA and IGF1R, uPAR is able to enhance the malignant potential of triple-negative breast cancer [41]. More importantly, high expression of UPAR is closely related to a poor prognosis [61]. In addition, studies have demonstrated that the decrease in the suPAR concentration after resection in patients with colorectal cancer [62] and pancreatic cancer [54] is associated with reduced mortality risk. Therefore, the expression level of uPAR can be assessed as a marker of tumor malignancy $[30,59,63]$.

\section{Regulatory network of UPAR in tumor cell proliferation}

Since uPAR lacks transmembrane or intracellular domains, it needs to interact with transmembrane receptors and complexes to trigger downstream signaling and promote tumor cell proliferation [4]. Recently, Wang K et al. [59] and Semina EV et al. [64] knocked out uPAR with the CRISPR/Cas9 system, successfully resulting in suppression of human cancer cell proliferation. Silencing uPAR can inhibit the expression of the MMP2, MMP9 and P-ERK proteins in oral and tongue squamous cell carcinoma and attenuate cell proliferation [65]. Research shows that the uPA-uPAR-a5 $\beta 1$ integrin complex can bind to G-protein-coupled receptors (GPCRs) to transmit signals and promote tumor cell proliferation [66]. The interaction of the uPA-uPAR-a5 $\beta 1$ integrin complex with EGFR enables the phosphorylation of Tyr397 and the Src homology 3 domain (SH3) in the intracellular domain of integrin a $5 \beta 1$; this leads to the activation of focal adhesion kinase (FAK, also known as PTK2) [67-69], which results in the activation of Ras and the expression of mitogen-activated protein kinase (MAPK). uPAR can also transactivate EGFR, mediating the UPAR-initiated mitogenic signal [70, 71] (Fig. 3A). The D2A motif in domain 2, which is as effective as EGF, can promote phosphorylation of EGFR and activation of the MAPK signaling pathway, thus facilitating cell proliferation [71]. D1 of UPAR is crucial for EGFR activation, and FAK links integrin and EGFR signaling. Inhibition of EGFR kinase blocks uPAR-induced ERK signaling, implicating EGFR as an important effector of the pathway [69] (Fig. 3B).

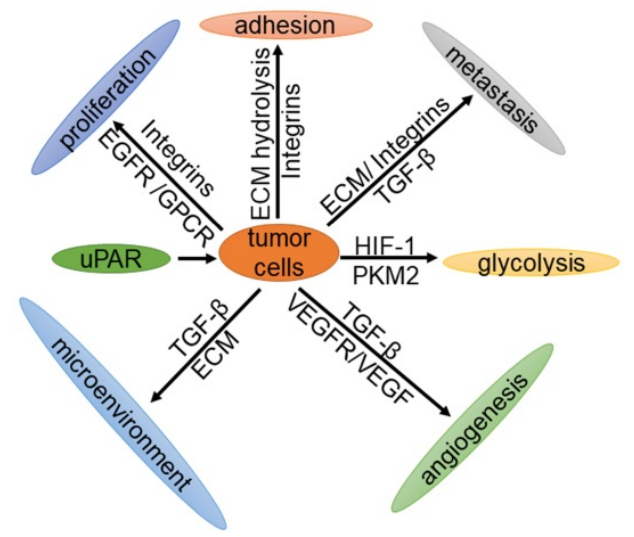

Figure 2. The function of tumor cells is regulated by uPAR. UPAR regulates the proliferation, metastasis, adhesion, glycolysis and angiogenesis of tumor cells through cell signaling, and plays an important role in the tumor microenvironment.

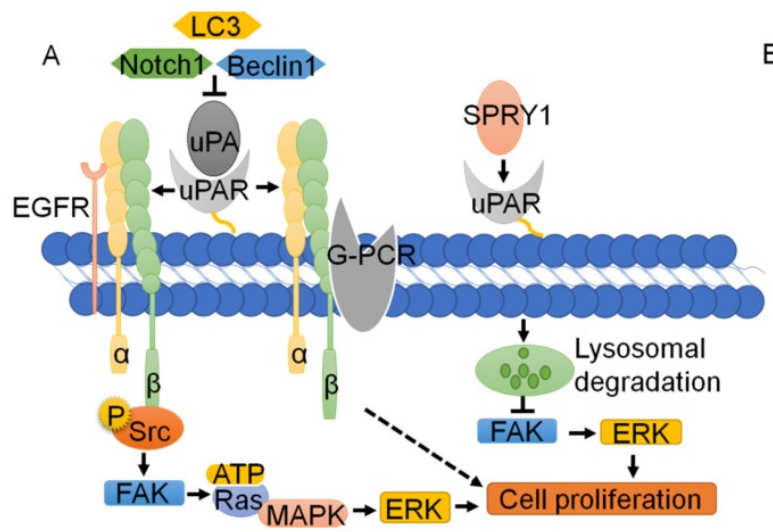

$B$

Figure 3. Function and regulation of uPAR in tumor cell proliferation. (A) The interaction of the uPA-uPAR- $\alpha 5 \beta 1$ integrin complex with EGFR enables the Src homology 3 domain $(\mathrm{SH} 3)$ in the intracellular domain of integrin $\alpha 5 \beta 1$; this leads to the activation of FAK, which results in Ras activation and MAPK expression. The uPA-uPAR- $\alpha 5 B 1$ integrin complex can bind to GPCR to transmit signals and promote tumor cell proliferation. SPRY1 can interact with uPAR and promote its lysosomal-mediated degradation, resulting in inhibition of the activation of the FAK and ERK pathways, which suppresses the tumor proliferation induced by uPAR. (B) DI and D2 of uPAR are crucial for EGFR activation, which is as effective as EGF in promoting MAPK and FAK, and cell proliferation. 


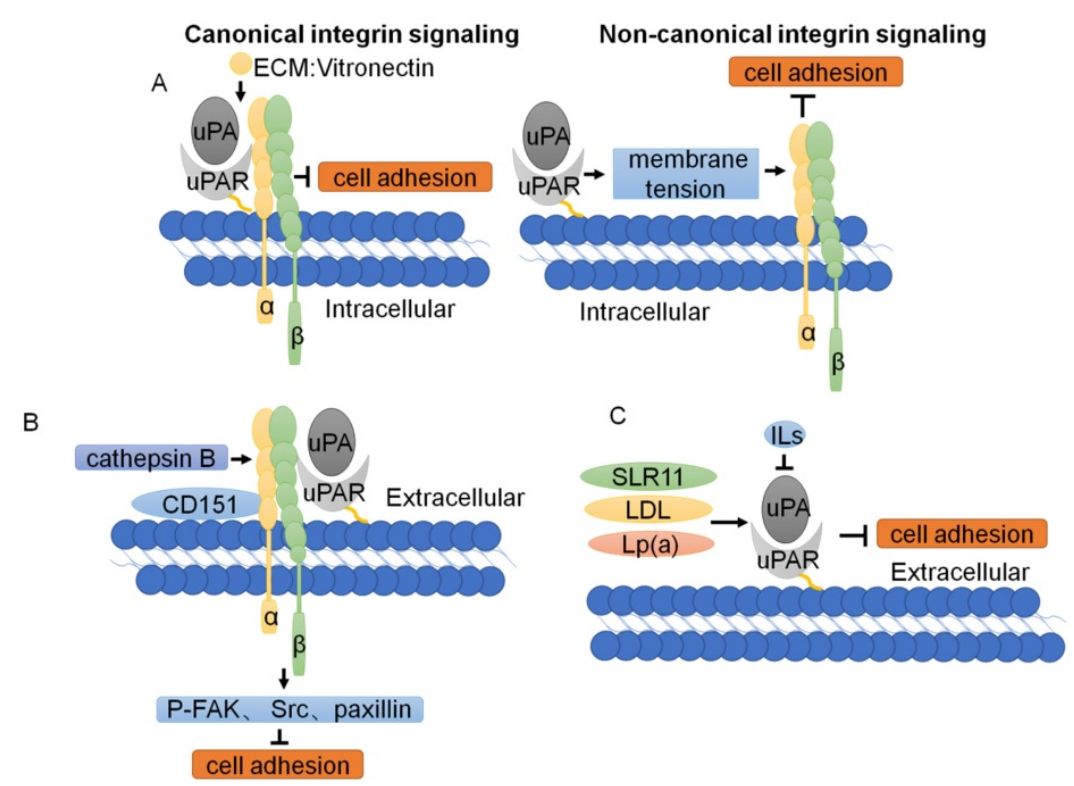

Figure 4. Function and regulation of uPAR in tumor cell adhesion. (A) Two modes of uPAR signal regulation. In canonical signaling, integrins engage the specific ligands in the ECM. In non-canonical integrin, uPAR-mediated cell adhesion, through the plasma membrane, transmits a mechanical stimulus to the integrin that signals independently of ECM binding. (B) The downstream signaling cascade of uPAR/CD151/a3ß1 integrin shows that phosphorylation of FAK, Src and paxillin is reduced with knockdown of cathepsin $\mathrm{B}$, uPAR, and CD151. (C) Other cellular proteins regulate tumor cell adhesion through uPAR.

Other signaling pathways are also involved in the proliferation mediated by uPAR. The Notch pathway is a highly conserved cellular signaling system that regulates the differentiation of a variety of cells and plays important roles in carcinogenesis. As reported, silencing Notch1 can inhibit the expression of $\mathrm{UPA}$ and its receptor $\mathrm{UPAR}$, thus inhibiting the proliferation of cancer cells [72]. SPRY1, an inhibitor of the Ras-MAPK pathway, can interact with uPAR and promote its lysosomal-mediated degradation, resulting in inhibition of the activation of the FAK and ERK pathways, which suppresses the tumor proliferation induced by uPAR [73-75]. Knockdown of LC3 and Beclin-1 leads to inhibition of uPAR/ integrin- $\beta 1 / \mathrm{Src}$ signaling pathways, thereby suppressing cancer cell proliferation and colony formation [76]. Loss of UPAR inhibits the PI3K/AKT pathway, while downregulation of UPAR leads to upregulation of P-ERK and forces cells to use the ERK pathway as an alternative pathway for growth and survival [77] (Fig. 3A). In short, uPAR typically binds to cell membrane surface proteins, such as integrin, EGFR and GPCR to promote cell proliferation, whereas binding of UPAR by its inhibitors leads to lysosome-mediated degradation of the UPAR, thus repressing of uPAR on the proliferation of tumor cells.

\section{Effect of the uPAR signaling pathway on tumor cell adhesion}

In addition to the regulation of cell proliferation by UPAR described above, uPAR also regulates cell adhesion $[77,78]$. Changes in the physical properties, composition, expression and regulation of the ECM are considered to be abnormal signals that alter tumor cell adhesion. uPAR can regulate cell adhesion by promoting ECM proteolysis and transmitting intracellular signals [4]. uPAR regulates cell adhesion by binding directly to vitronectin and by forming complexes with integrins [79]. Recent studies have shown that cleavage of vitronectin by uPA displays a remarkable receptor dependence and requires concomitant binding of both uPA and vitronectin to uPAR, which induces cell adhesion [13]. In contrast to canonical integrin signaling, uPAR-mediated cell adhesion to vitronectin triggers a novel type of integrin signaling that is independent of integrinengagement. The molecular mechanism enabling the crosstalk between nonintegrin adhesion receptors and integrins is dependent on membrane tension [80] (Fig. $4 \mathrm{~A})$.

As mentioned above, the change in tumor cell adhesion is regulated by UPAR expression. Overexpression of uPAR can strongly upregulate MMP expression and enhance breast cancer cell adhesion [78]. sLR11 regulates the hypoxia-enhanced adhesion of hematopoietic stem and progenitor cells (HSPCs) via an uPAR-mediated pathway[81]. LDL and $L p(a)$ lipoproteins increase the expression of uPA and UPAR on monocytes, affecting plasmin generation and monocyte adhesion. The cytokines IL-4, IL-10 and IL-13 induce a decrease in uPAR expression and lead to a change in tumor cell adhesion [82] (Fig. 4C). Studies on the downstream signaling cascade of uPAR/CD151/integrin a3 $\beta 1$ have shown that phosphorylation of FAK, Src, and paxillin and expression of the adaptor cytoskeletal 
proteins talin and vinculin are reduced with knockdown of cathepsin B, uPAR, and CD151 [83] (Fig. 4B). Collectively, these data demonstrate that UPAR regulates tumor adhesion through complex mechanisms.

\section{Effects of the uPAR signaling pathway on tumor metastasis}

UPAR is widely expressed on the surface of endothelial cells, fibroblasts and a variety of malignant tumor cells and exerts functions in cancer cell migration and tumor metastasis [14]. As reported, uPAR regulates malignant tumors through integrins on breast cancer [84] and pancreatic ductal adenocarcinoma cells [85]. Different studies have stressed that the regulatory effects of uPAR on tumor metastasis through other signaling pathways, such as those related to the ECM, integrins, and TGF- $\beta 1$.

\section{ECM}

Since uPAR lacks transmembrane and intracellular domains [4], it needs to interact with transmembrane receptors, such as ECM receptors and integrins, to activate intracellular signals. The ECM is required for cell movement and is a physical barrier to cell movement. Cell migration often involves the decomposition of ECM proteins [86]. uPAR activates a variety of intracellular signaling pathways that promote cell invasion by regulating ECM proteolysis and synergistic actions with transmembrane receptors [4]. In tumor tissues, the interaction of uPA and UPAR leads to proteolysis of the ECM through a cascade reaction. After $\mathrm{uPA}$ binds to $\mathrm{uPAR}$, the inactive pro-uPA precursor is transformed into active uPA. Then, uPA cleaves inactive plasminogen into active plasmin, which further cleaves and activates downstream matrix metalloproteinases (MMPs) [87]. The fibrinolytic proteases and MMPs formed after activation will hydrolyze ECM and release active EGF, which promotes tumor invasion and metastasis [88]. uPAR can also degrade ECM through the proteasome pathway and activate MMPs to degrade ECM and activate EGF to further regulate the cell membrane ECM interaction, in addition to enhancing cell migration and signal transduction through the binding of and interaction between vitronectin and integrins [86, 89]. VEGF165 interacting with its receptor VEGFR-2 rapidly induces pro-uPA activation that is dependent on a change in integrin affinity, activation of MMP-2 and pro-uPA being bound to its surface receptor UPAR [90]. Taken together, UPAR is an important ECM proteolysis protein that regulates the interaction between cells and the ECM as well as cell migration [4] (Fig. 5A).
Integrins

Integrins are important cell adhesion receptors and play substantial roles in the progression of tumor metastasis [91]. uPAR and integrins form stable complexes that both inhibit native integrin adhesive function and promote adhesion to vitronectin via a ligand binding site on UPAR [92]. The uPAR and integrin a5 $\beta 1$ interaction promotes tumor cell migration. uPAR is required to activate integrin a $5 \beta 3$ in podocytes, promoting cell motility and activating the small GTPases Cdc42 and Rac1. Blockade of integrin a5 $\beta 3$ reduces podocyte motility in vitro and lowers proteinuria in mice [93]. The uPAuPAR-integrin a5 $\beta 1$ complex drives activation of the GTPase Rac and actin assembly. Actin protrusions from the cell wall extend forward, and pericytes outside the cytoplasmic membrane protein undergo a decomposition of pericyclic proteins, which eliminates the ECM barrier outside the cell membrane and membrane processes [94]. The glycolytic enzyme alpha-enolase (ENO1) also acts as a plasminogen receptor, controls integrin a5 $\beta 3$ expression and upregulates pancreatic cancer invasion, and metastasis [85]. The major downstream uPAR/ integrin signaling (especially $\beta 1$ and $\beta 3$ ) involve activation of Src, PI3K/AKT, and MEK/ERK1-2 pathways [26]. Furthermore, uPAR cooperates with integrin complexes containing integrin $\beta 3$ to drive formation of the p130Cas-CrkII signaling complex and activation of Rac, resulting in a Rac-driven elongated-mesenchymal morphology, cell motility and invasion [95]. UPAR interaction with vitronectin initiates a p130Cas/Rac-dependent signaling pathway, leading to actin reorganization and increased cell motility [96]. Activated Rac can also stimulate actin polymerization, leading to the assembly of filamentous myosin, and ultimately stimulate membrane processes, leading to cell migration and invasion [96]. In addition, integrinUPAR signaling can lead to the phosphorylation of Fos-related antigen-1 (FRA-1), promoting the invasion of breast cancer cells [84] (Fig. 5B).

\section{TGF- $\beta$ and EMT}

Tumor cell metastasis typically requires activation of TGF- $\beta 1$ to control physiological processes [97] TGF- $\beta$ signaling through mitogenactivated protein kinase, c-Jun-NH2-kinase, p38, PI3K, and G-proteins may be responsible for some of the oncogenic effects that occur in tumor cell migration and invasion [98]. TGF- $\beta 1$ induces invasion in malignant meningioma cells with an associated upregulation of uPA, uPAR, cathepsin B and MMP-9, and activation of intracellular signals of the H-RAS, ERK/PI3K, XIAP and MAPK pathways [99-101]. In 
addition, TGF- $\beta$, MMPs and the uPA/uPAR system can induce epithelial-mesenchymal transition (EMT) in cancer cells $[102,103]$. Interestingly, TGF- $\beta$ can induce MMPs expression, and MMPs can in turn activate TGF- $\beta$, promoting EMT in cancer cells [104]. $\mathrm{uPA} / \mathrm{uPAR}$ expression induces EMT in tumor cells by mediating TGF- $\beta$, resulting in tumor progression and metastasis [103, 105]. Furthermore, TGF- $\beta$ RII is required for TGF- $\beta$ activation of JNK1 and the resulting upregulation of uPAR expression. TGF- $\beta$ activates the Ras/MKK4/JNK1 signaling cascade, leading to induction of AP-1 activity, which, in turn, up-regulates uPAR expression [106] (Fig. 5C). In addition, as mentioned above, UPAR expression is closely related to EMT. Recent studies have shown that UPAR upregulation in melanoma cells exposed to mesenchymal stem cell (MSC)-medium drives TGF $\beta$ mediated EMT [107]. The transcription factor Forkhead box M1 (FOXM1) promote cancer EMT and metastasis by enhancing UPAR gene transcription [108], while uPAR downregulation inhibits cancer EMT and dysregulation EMT biomarker proteins [64, $103,107]$. TGF- $\beta$-induced uPA expression is human telomerase reverse transcriptase (hTERT)-dependent, and a positive association exists between hTERT and
uPA [101]. Taken together, it is clear that both TGF- $\beta$ and $\mathrm{uPA} / \mathrm{uPAR}$ collaborate in the induction of cancer-associated EMT.

\section{Non coding RNA}

MicroRNAs are small, noncoding singlestranded RNAs that negatively regulate gene expression at the posttranscriptional level. MicroRNAs can inhibit the expression of uPAR directly and indirectly in a variety of cancer types [34]. Targeted delivery of antisense-miR-21 and antisensemiR-10b coloaded in uPAR-targeted polymer nanoparticles (NPs)-treated mice show a substantial reduction in tumor growth [109]. As reported, miR-378a-5p and miR-23a promote tumor cell metastasis by upregulating the expression of uPAR $[110,111]$. However, miR-324-5p, miR-193b and miR-143 can inhibit the expression of uPA and UPAR, thus inhibiting the migration and invasion of cancer cells [112-114]. Recently studies show that miR-200s regulate ECM remodeling, which trigger tumor cell invasion [115]. Taken together, uPAR is regulated by microRNAs to exert ECM remodeling, which plays an important role in the metastasis of cancer cells (Fig. 5D).

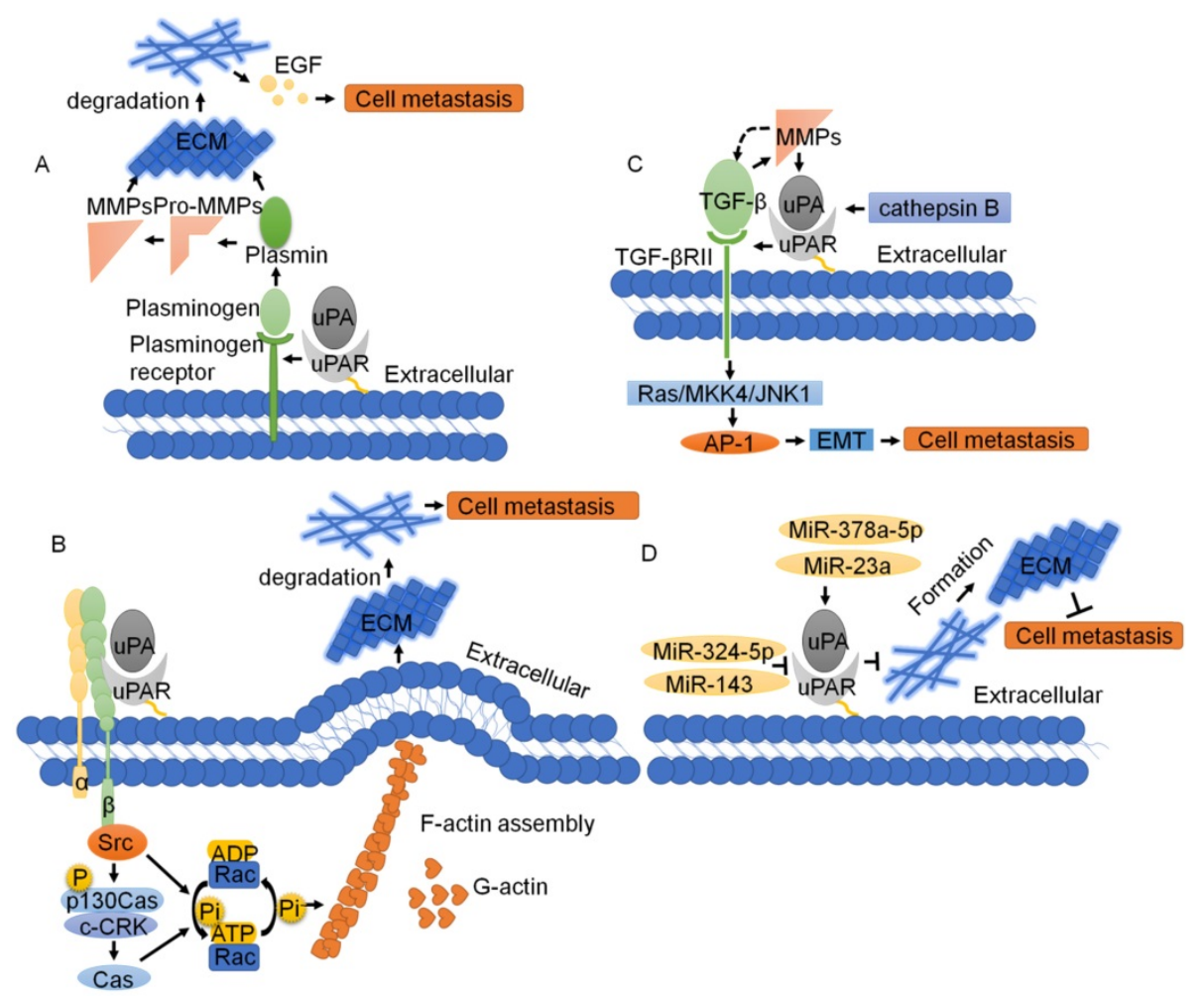

Figure 5. The regulatory network of uPAR through the ECM, integrin, TGF- $\beta$ and noncoding RNA in tumor migration. (A) uPA binds to uPAR, and the inactive pro-uPA precursor is transformed into active uPA. Then uPA cleaves inactive plasminogen into active plasmin, which further cleaves and activates downstream MMPs. The fibrinolytic proteases and MMPs formed after activation will hydrolyze ECM and release active EGF, which promotes tumor invasion and metastasis. (B) Integrin and uPA/uPAR form the structure of the uPA-uPAR integrin complex signal, and drive the activation of GTPase Rac actin assembly, the cell wall of actin protrusions extends forward, and pericytes outside the cytoplasmic membrane protein (pericyclic protein) decomposition are eliminated outside the ECM barrier membrane. (C) TGF- $\beta 1$ induces epithelial-mesenchymal transition (EMT) with an associated upregulation of uPA, uPAR, cathepsin B and MMP-9. TGF- $\beta$ activates the Ras/MKK4/JNK1 signaling cascade, leading to the induction of AP-1 activity, which promotes cell migration. (D) MicroRNAs regulate uPAR-induced ECM formation and protein degradation, which play an important role in cancer cell metastasis. 


\section{Other factors}

Studies have also revealed that uPAR can interact with formyl peptide receptors (FPRs) to promote cell migration [116]. The uPAR88-92 sequence can interact with FPR1, and inhibition of uPAR/FPR1 crosstalk may be useful for the treatment of metastatic epithelial ovarian cancer (EOC) [51, 116]. Moreover, the S90P and S90E substitutions in the UPAR protein can cause upregulation and downregulation of cell migration, respectively, by mediating agonist-triggered activation and internalization of FPR1 [117], thus inhibiting tumor metastasis [116]. In addition, uPAR can enhance the metastasis and invasion induced by Ras mutations in tumor cells [118]. In human AGS gastric cancer cells, uPAR can be stimulated by prostaglandin E2 via the EP2 receptor-dependent Src/EGFR/JNK1/2, Erk1/ 2/AP-1, Src/EGFR/JNK1/2, and Erk1/2/NF-kB signaling pathways, thereby promoting tumor metastasis [119]. As a co-receptor, uPAR is recycled on the cell surface and redistributed to the invasive side of cancer cells, further enhancing the migration and invasion abilities of cancer cells [4].

Different studies have stressed that UPAR has contributory effects on tumor metastasis through other signaling pathways. Silencing of UPAR inhibits the invasion and migration of oral tongue squamous cell carcinoma cells by regulating the expression of MMP2, MMP9 and p-ERK [65]. PDZ-binding kinase (PBK) can bind directly to the core region of the UPAR promoter through ETV4 to regulate the metastasis of hepatocellular carcinoma [120]. In bladder cancer, UPAR can regulate the mammalian target of rapamycin complex (mTORC) signaling pathway. uPAR silencing inhibits AKT phosphorylation at Ser473, inhibiting cell migration and invasion [37].

\section{Regulatory network of UPAR in glycolysis}

Normal cells rely on mitochondrial oxidative phosphorylation to produce ATP, while cancer cells, which are not affected by the partial pressure of oxygen, are able to gain energy via glycolysis with the stimulation of hypoxia-inducible factor (HIF-1a) [6]. As early as 1997, Anichini E and colleagues discovered that UPAR plays an important role in glycolysis [121]. The interaction of uPA with uPAR rapidly induces the activation of glucose transporters. In recent years, studies have found that hypoxia can enhance the expression of endogenous uPAR in a HIF-1a-dependent manner [122]. As reported, activation of HIF-1 $\alpha$ can upregulate uPAR expression and activate its associated signals [123, 124], while inhibition of HIF-1a gene expression can downregulate the mRNA and protein levels of Upar [125]. Mechanistically, inhibition of uPAR with siRNA or uncoupling of uPAR from integrin-linked tyrosine receptors (IL-TKRs) will inhibit the PI3K/AKT/ mTOR/HIF1a signaling pathway, resulting in impaired glucose uptake and a reduction of pyruvate kinase-2 (PKM2) and other glycolytic enzymes, thereby controlling the metabolism of cancer cells [6]. In addition, phosphoinositide-dependent protein kinase-1 (PDK1) can inhibit glycolysis in cancer cells [126]. Downregulation of PDK1 through the use of siRNAs targeting uPAR leads to the downregulation of downstream P-Akt [127, 128] (Fig. 6).

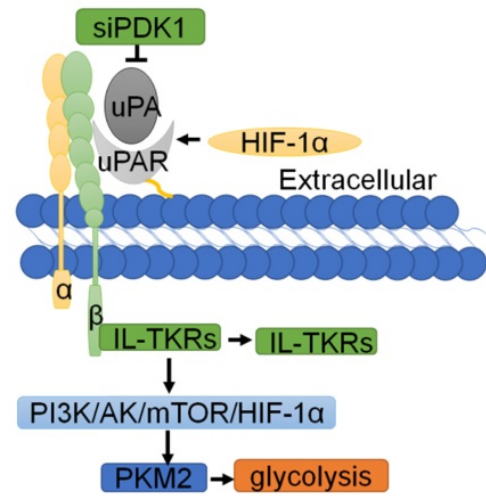

Figure 6. The regulatory network of uPAR in glycolysis. Hypoxia can enhance the expression of endogenous UPAR in a HIF-1a dependent manner. Inhibition of uPAR with siRNA or uncoupling of uPAR from integrin-linked tyrosine receptors (IL-TKRs) inhibits the PI3K/AKT/mTOR/HIF-la signaling pathway, resulting in impaired glucose uptake and a reduction in PKM2 and other glycolytic enzymes, thereby controlling the metabolism of cancer cells.

\section{Regulatory network of UPAR in the tumor microenvironment}

A study focused on the microenvironment of colorectal tumors found that UPAR is expressed in macrophages, neovascular endothelial cells and myofibroblasts, and its expression is negatively correlated with survival rates [32]. Another study also showed that UPAR contributes to vascular permeability, resulting in changes in the inflammatory microenvironment in ovarian cancer [129]. In breast cancer, researchers have established a mathematical model of cancer recurrence focusing on monitoring of tissue biomarkers, including markers in the plasminogen system, and found that only the serum concentration of UPAR in cancer patients was positively correlated with cancer recurrence [130]. The interaction of UPA with UPAR activates a network of interconnected signaling pathways and induces and activates the tumor microenvironment regulatory factor TGF- $\beta$ [100], which in turn promotes the expression of $\mathrm{uPA}$ and thus forms a positive feedback loop [131]. TGF- $\beta$ function through proteolytic degradation of the ECM and regulates the expression of several MMPs and uPA/uPAR in cancer cells, thus contributing to tumor malignancy [103, 132]. uPAR 
also controls the expression of the tumor microenvironment regulator IL-4 in cancer cells by activating the ERK1/2 pathway $[133,134]$.

\section{Role of UPAR in tumor-associated angiogenesis}

Angiogenesis plays a critical role in physiological and tumor pathological processes [135]. The blood vessels allow blood to reach all parts of the growing tumor mass, providing nutrients and oxygen, and allow invading tumor cells to reach distant sites for colonizatione. New blood vessels can sprout from pre-existing angiogenesis or can form by endothelial progenitor cells (EPCs) [136]. During angiogenesis, endothelial cells (ECs) degrade basement membrane, migrate through the ECM, proliferate and organize in new vessels, which can include locally recruited EPCs. UPAR activation consequent to the binding of uPA can be regarded as an "angiogenic switch" [137]. uPAR focuses on the proteolytic activity of uPA on the endothelial cell surface, thus promoting angiogenesis in a proteasedependent manner. In endothelial cells, uPAR interacts with VEGFR2, which mediates VEGF signaling and promotes angiogenesis [138]. VEGF165, the major angiogenic growth factor that initiates angiogenesis, requires coordinated proteolytic degradation of extracellular matrix provided by the $\mathrm{uPA} / \mathrm{uPAR}$ system and regulation of cell migration provided by integrin-matrix interaction [66, 139]. Evidence shows that VEGF165, VEGF-E, FGF-2, EGF and HGF induced PI3K-dependent activation of pro-uPA when bind to uPAR, which leads to an increase in cell surface fibrinolytic activity [140]. Thus, UPAR represents a central mediator of growth factor-induced endothelial cell migration.

The amoeboid and mesenchymal types of invasiveness are two modes of interchangeable migration in cancer cells. A recent study showed that a role of the UPAR-integrin-actin axis in the regulation of amoeboid angiogenesis. UPAR is indispensable for ECs and ECFCs to perform efficient amoeboid angiogenesis [141]. UPAR is also functionally important in fostering angiogenesis in EPCs [142] and ECFCs [143] upon recruitment in caveolar-lipid rafts. Gangliosides and UPAR typically partition into specialized membrane microdomains called lipidrafts. The cell membrane enrichment with exogenous GM1 ganglioside is pro-angiogenic, with the opposite effect of cell membranes enriched with GM3 ganglioside. Following GM1 exogenous addition, the GM3 compartment is depleted of uPAR which is recruited within caveolar rafts thereby triggering angiogenesis [142]. Endothelial UPAR is also thought to provide a regulatory mechanism in angiogenesis.
The proangiogenic role of UPAR in ECFCs, depends on the integrity of caveolae and the presence of fulllength UPAR in specialized membrane invaginations. Inhibition of UPAR expression promoted caveolae disruption. VEGF promoted the accumulation of UPAR in ECFCs caveolae in its undegraded form. VEGF-dependent ERK phosphorylation required integrity of caveolae as well as caveolar UPAR expression. Interestingly, overexpression of matrix metalloproteinase-12 (MMP-12) blocks angiogenesis by cleavage of endothelial uPAR [144], which impairs angiogenesis in SSc [145]. MMP12- dependent uPAR cleavage results into the loss of invasion properties and angiogenesis [146]. VEGF activity depends on inhibition of ECFC MMP12 production, which impairs MMP12-dependent uPAR truncation. MMP12 overexpression in ECFCs inhibits vascularization in vitro and in vivo [143]. Angiogenesis and tumor promotion are active in late stages of tumor progression by TGF- $\beta$. Evidence shows that TGF- $\beta$ upregulates the expression of uPAR to reguate pro-angiogenic activity in human normal dermal MVEC [147]. Inhibition of GDF5 in TGFß-stimulated ECs impairs TGFß-dependent UPAR overproduction, impairing angiogenesis [148]. Exosomes is a new vesicular lipid transporter that is involved in various pathophysiologies. uPAR-expressing melanoma exosomes promote angiogenesis by VE-cadherin, EGFR and UPAR overexpression and increase ERK1/2 signaling in endothelial cells [149, 150]. Tumor suppressor phosphatase and tensin homologue (PTEN) expression in endothelial cells is downregulated by uPAR to activate the PI3K/Akt pathway and support angiogenesis [151]. Mice deficient in UPAR provided an opportunity to assess the role of uPAR during angiogenesis in vivo. In uPAR(-/-) mice, dermal fibrosis is paralleled by endothelial cell apoptosis and a severe loss of microvessels [152]. Similarly, tumor growth of subcutaneously injected murine prostate cancer cells is significantly retarded in uPAR-deficient mice compared with wild-type mice [153]. In conclusion, uPAR plays an important role in angiogenesis in vivo and in vitro.

\section{uPAR and cancer therapy}

\section{UPAR and chemoradiotherapy}

Chemoradiotherapy (CRT) plus surgery for locally advanced cancer has recently become the standard therapeutic strategy and has a significant survival benefit compared with surgery alone [154-156]. Some studies have attempted to accurately assess CRT responses with different diagnostic approaches, but the results have mostly been 
unsatisfactory. Therefore, reliable and effective biomarkers to predict the sensitivity and response of advanced tumors to CRT are urgently needed to promote individualized treatment. A recent study investigated the profiles of cytokines related to EGF and UPAR in 68 esophageal squamous cell carcinoma (ESCC) patients. The data indicated that upregulation of UPAR- and EGF-related cytokines after CRT is associated with poor progression-free survival and shortened survival [156]. The levels of EGF and UPAR for CRT in serum are reliable and predictive biomarkers for survival in ESCC patients [156]. However, the expression of uPAR is dramatically upregulated after CRT [157], and recent results suggest that PAI-1 but not uPA and UPAR might have prognostic value for patients with advanced non-small-cell lung cancer (NSCLC) undergoing radiotherapy [158]. Therefore, the response of individual tumors to CRT is highly variable.

\section{uPAR and targeted therapy}

The UPAR system regulates cell proliferation, adhesion, invasion, and migration as well as glycolysis and the microenvironment. PAI-1 mediates the endocytosis of UPAR and blocks its biological function, thus inhibiting tumor development [159]. Therefore, UPAR can be used as a marker for cancer prognosis and diagnosis and is an attractive therapeutic target $[4,160]$. Quercetin has been proven to induce antimetastatic effects in gastric cancer cells by suppressing the uPA/uPAR system via modulation of various associated pathways, including the NF-kb, PKC- $\delta$, ERK1/2, and AMPKa pathways, indicating that uPAR may be a potential target for the treatment of gastric cancer [161]. The plant flavonoid 2',3,4',5,7-pentahydroxyflavone can effectively inhibit the expression of uPA and uPAR and inhibit TPA-induced metastasis of human breast cancer cells through the Akt/GSK-3 $\beta /$ C-FOS pathway [162]. Moreover, apigenin plays an anti-invasive role by mediating the (ERK1/2, JNK)/AP-1 and (ERK1/2, JNK)/NF-KB signaling pathways to inhibit the expression of UPAR [163]. As UPAR and FPR1 are both involved in tumor progression, an effective cell migration peptide inhibitor (Ac-d-Tyr-d-Arg-AIB-dArg-NH) has been synthesized to inhibit the interaction of UPAR and FPR1 to suppress migration and angiogenesis [116, 164]. Another study also stressed that inhibitors of uPAR84-95/FPR1 crosstalk may be useful for the treatment of metastatic melanoma [165]. 2G10, a recombinant antibody that binds to UPAR to form a stable complex and can block the interaction of uPA-uPAR, is effective in a xenotransplantation model of highly aggressive, triple-negative breast cancer (TNBC) [166]. Anti-
UPAR small molecules that specifically inhibit the uPAR-vitronectin interaction can inhibit cell adhesion and migration, representing a novel tool for NSCLC and colorectal cancer patients carrying Ras mutations [118].

\section{UPAR and immunotherapy}

Chimeric antigen receptors (CARs) are synthetic receptors that can alter the specificity and other functions of $T$ cells $[167,168]$. Preventing the occurrence of various diseases caused by the accumulation of cellular senescence is important for immunotherapy of tumors and other diseases [169]. Thus, CAR-T cells that counter aging-associated changes exhibit broad therapeutic potential [167, 170]. uPAR is widely expressed on the surface of senescent cells, and uPAR-targeted CAR-T cells can eliminate senescent cells in vitro and in vivo [167]. In T cells, the CAR includes an extracellular uPAR-specific ligand binding domain $(\mathrm{scFv})$, an intracellular costimulatory domain (from molecules such as CD28 or 4-1BB) and a CD3 $\zeta \mathrm{T}$ cell activation domain, which is activated by the binding of uPAR, leading to the activation and granule shedding of intracellular $T$ cells $[171,172]$. suPAR can be used as a plasma biomarker to evaluate the anti-aging activity of CAR-T cells in vivo [173]. Therefore, uPAR can be used as a target for CAR-T cell therapy in cancers [174] (Fig. 7). These works provide promising preliminary evidence that uPAR-directed CAR-T cells effectively target senescent cells and show that this CAR T-cell treatment has a measurable impact on disease states in immunocompetent hosts.

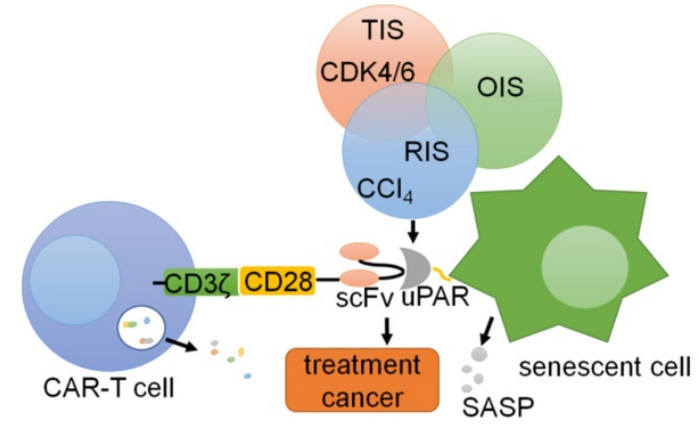

Figure 7. CAR-T cells targeting uPAR can be utilized for cells. UPAR is identified as a common upregulated marker in senescent cells in three different models: therapy-induced senescence (TIS), oncogene-induced senescence (OIS), and replication-induced senescence (RIS). Senolytic CAR T cells were generated by introducing anti-mouse uPAR scFv linked to human CD28 costimulatory and CD3 $\zeta$ signaling domains, resulting in T cell activation and degranulation.

Antibodies against uPAR can inhibit pericellular hydrolysis, thus blocking the downstream signaling pathways activated by UPAR as well as tumor growth and metastasis [175, 176]. huATN-658, a humanized anti-uPAR antibody, can significantly decrease tumor cell proliferation and metastasis [177]. Leukocyte 
immunoglobulin- like receptor B4 (LILRB4) is an inhibitory immune receptor that is more highly expressed in monocytic AML cells than in normal monocytes [178]. A recent study revealed that LILRB4 can regulate different signaling pathways, including the UPAR pathway, suppress $\mathrm{T}$ cell activity and promote the proliferation of leukemia cells [178]. Therefore, the detection or targeting of UPAR in immunotherapy may also be of interest.

\section{UPAR and cell drug resistance}

Cell drug resistance can occur over time in the treatment of cancer and results in the weakening of drug effects, which is one of the causes of cancer-related death [179]. To reduce drug resistance, combination drug therapy has become an important method for effective treatment of cancer [180]. Exosomes are extracellular vesicles ranging in size from $40 \mathrm{~nm}$ to $100 \mathrm{~nm}$ that are often secreted by tumor cells and multiple stromal cells in the tumor microenvironment, and they can enhance drug resistance [128, 181]. The expression of uPAR is an important reason for cetuximab resistance in patients with oral squamous cell carcinoma, and combination therapy with resveratrol, which can inhibit the expression of uPAR, may provide an attractive means for treating these patients [182]. Knocking out the uPAR gene via the CRISPR/Cas9 system can reduce the resistance of tumor cells to 5-FU, cisplatin, docetaxel and Adriamycin [59]. BRAF inhibitor (BRAF-I) therapy for melanoma patients is initially highly effective, but drug resistance greatly limits its application. A recent study demonstrated that UPAR knockdown in combination with vemurafenib administration can inhibit melanoma cell proliferation by decreasing the phosphorylation of AKT and ERK1/2, and overexpression of uPAR results in reduced sensitivity to BRAF inhibition [183]. Researchers have also found that an anti-uPAR antibody (HuATN-658) combined with bisphosphonate zoledronic acid (Zometa) can inhibit breast cancer growth and bone lesions by targeting uPAR [177].

\section{Conclusions and prospects}

Tumorigenesis and progression via the UPAR signaling pathway have emerged as hot topics in the field of cancer research. uPAR is a GPI type multifunctional receptor that mainly binds to ligand molecules released by ECM hydrolysis, such as uPA and vitronectin, and then combines with integrins and G-PCR on the cell membrane to transmit the signal intracellularly [184]. This review provides an overview of emerging data, from basic research as well as cancer therapy, highlighting the evolving role of UPAR in tumor progression. It is currently believed that UPAR expression plays an important role in tumorigenicity, and high endogenous uPAR levels are associated with tumor proliferation, advanced metastatic cancers, and glycolytic capacity [185]. UPAR has also been implicated in the angiogenesis of several solid and hematologic malignancies [186]. UPAR is aberrantly expressed through activation of signaling pathways by genetic alterations, oncogenes, transcription factors, and microenvironmental influences. Additionally, various therapeutic strategies have emerged in preclinical animal testing and clinical trials to inhibit the functions of UPAR in cancer therapy. However, the clear molecular mechanism need to be further investigated in immune escape.

Targeted UPAR immunotherapy has not achieved the desired effects in the treatment of various types of cancers. One reason for this inconsistent and poor response may be related to individual differences among patients as well as tumor heterogeneity within a single patient. Therefore, the search for targeted drugs that can inhibit the binding of UPAR and UPAR target proteins as well as other membrane proteins has become extremely important [187]. Some small molecules and antibodies that can either suppress the expression of UPAR or block the interaction between UPAR and related membrane proteins are able to inhibit the development of tumors. A combination of resveratrol and cetuximab inhibits the expression of UPAR and has been used to treat cancer [184]. Moreover, uPAR-targeted CAR-T cells can eliminate senescent cells in vitro and in vivo [167], indicating the broad therapeutic potential of uPAR in immune therapy. Coronavirus disease 2019 (COVID-19) is characterized by suppressed lung fibrinolysis. Recent studies have shown that uPA can regulate alveolar type 2-mediated re-alveologenesis [188]. The expression of suPAR is highly correlated with the characteristics of COVID-19 patients. Thus, studies of the uPA/uPAR system are helpful for identifying drugs to prevent or even treat COVID-19 [189]. As such, further analyses of immune therapy and disruption of the interactions between UPAR and its coreceptors represent an attractive strategy for targeting aggressive malignancies.

\section{Abbreviations}

uPA: Urokinase-type plasminogen activator receptor; uPAR: Urokinase-type plasminogen activator; suPAR: soluble type of uPAR; ECM: Extracellular matrix; GPI: Glycosyl phosphatidyl inositol; RGD: Arginine-glycine-aspartic acid; SMB: Somatomedin-B; PAI-1: Plasminogen activator 
inhibitor-1; PAI-2: Plasminogen activator inhibitor-2; MMPs: Mitochondrial Membrane Potentials; PET: Positron emission tomography; G-PCR: G-proteincoupled receptors; EGF: Epidermal Growth Factor; EGFR: Epidermal Growth Factor Receptor; FAK: Focal adhesion kinase; MAPK: Mitogen activator protein kinase; ERK: Extracellular signal-regulated kinase; TGF- $\beta$ : Transforming growth factor- $\beta$; VEGF: Vascular endothelial growth factor; ENO1: Enzyme alpha-enolase1; EMT: Epithelial-mesenchymal transition; FPRs: Formyl peptide receptors; EOC: Epithelial ovarian cancer; mTORC: mammalian target of rapamycin complex; HIF-1a: Hypoxia-inducible factor-1a; IL-TKRs: Integrin-linked tyrosine receptors; KM2: Pyruvate kinase-2; PDK1: phosphoinositidedependent protein kinase-1; CRT: Chemoradiotherapy; ESCC: Esophageal squamous cell carcinoma; NSCLC: Non-small-cell lung cancer; TNBC: Triplenegative breast cancer; CARs: Chimeric antigen receptors; LILRB4: Leukocyte immunoglobulin-like receptor B4; Zometa: Zoledronic acid; COVID-19: Coronavirus disease 2019; EPCs: endothelial progenitor cells; ECs: endothelial cells; PTEN: phosphatase and tensin homologue; hTERT: human telomerase reverse transcriptase; FOXM1: Forkhead box M1.

\section{Acknowledgements}

This work was supported by National Natural Science Foundation of China (NSFC) grant (31801175, 81601602), Yunnan Fundamental Research Projects (202101AT070043), National College Students' innovation and entrepreneurship training program of China (202010684006), Fund of Chengdu Medical College (CYZ16-03) and Key Project of the Education Department of Sichuan Province (18ZA0162).

\section{Competing Interests}

The authors have declared that no competing interest exists.

\section{References}

1. Lv T, Wu X, Sun L, Hu Q, Wan Y, Wang L, et al. p53-R273H upregulates neuropilin-2 to promote cell mobility and tumor metastasis. Cell death \& disease. 2017; 8: e2995.

2. Hu L, Liang S, Chen H, Lv T, Wu J, Chen D, et al. DeltaNp63alpha is a common inhibitory target in oncogenic PI3K/Ras/Her2-induced cell motility and tumor metastasis. Proc Natl Acad Sci U S A. 2017; 114: E3964-e73.

3. Lv T, Lv H, Fei J, Xie Y, Lian D, Hu J, et al. p53-R273H promotes cancer cell migration via upregulation of neuraminidase-1. Journal of Cancer. 2020; 11: 6874-82.

4. Smith HW, Marshall CJ. Regulation of cell signalling by uPAR. Nat Rev Mol Cell Biol. 2010; 11: 23-36.

5. Tjwa M, Sidenius N, Moura R, Jansen S, Theunissen K, Andolfo A, et al. Membrane-anchored UPAR regulates the proliferation, marrow pool size, engraftment, and mobilization of mouse hematopoietic stem/progenitor cells. J Clin Invest. 2009; 119: 1008-18.
6. Laurenzana A, Chillà A, Luciani C, Peppicelli S, Biagioni A, Bianchini F, et al. uPA/uPAR system activation drives a glycolytic phenotype in melanoma cells. International journal of cancer. 2017; 141: 1190-200.

7. Vassalli JD, Baccino D, Belin D. A cellular binding site for the Mr 55,000 form of the human plasminogen activator, urokinase. J Cell Biol. 1985; 100: 86-92.

8. Casey JR, Petranka JG, Kottra J, Fleenor DE, Rosse WF. The structure of the urokinase-type plasminogen activator receptor gene. Blood. 1994; 84: 1151-6.

9. Blasi F, Sidenius N. The urokinase receptor: focused cell surface proteolysis, cell adhesion and signaling. FEBS Lett. 2010; 584: 1923-30.

10. Ploug M, Ellis V, Danø K. Ligand interaction between urokinase-type plasminogen activator and its receptor probed with 8-anilino-1naphthalenesulfonate. Evidence for a hydrophobic binding site exposed only on the intact receptor. Biochemistry. 1994; 33: 8991-7.

11. Huai Q, Zhou A, Lin L, Mazar AP, Parry GC, Callahan J, et al. Crystal structures of two human vitronectin, urokinase and urokinase receptor complexes. Nat Struct Mol Biol. 2008; 15: 422-3.

12. Huai Q, Mazar AP, Kuo A, Parry GC, Shaw DE, Callahan J, et al. Structure of human urokinase plasminogen activator in complex with its receptor. Science. 2006; 311: 656-9.

13. De Lorenzi V, Sarra Ferraris GM, Madsen JB, Lupia M, Andreasen PA, Sidenius N. Urokinase links plasminogen activation and cell adhesion by cleavage of the RGD motif in vitronectin. EMBO Rep. 2016; 17: 982-98.

14. Noh H, Hong S, Huang S. Role of urokinase receptor in tumor progression and development. Theranostics. 2013; 3: 487-95.

15. Mekkawy $\mathrm{AH}$, Pourgholami $\mathrm{MH}$, Morris DL. Involvement of urokinase-type plasminogen activator system in cancer: an overview. Med Res Rev. 2014; 34: 918-56.

16. van Veen M, Matas-Rico E, van de Wetering K, Leyton-Puig D, Kedziora $\mathrm{K}$, De Lorenzi $\mathrm{V}$, et al. Negative regulation of urokinase receptor activity by a GPI-specific phospholipase C in breast cancer cells. eLife. 2017; 6 .

17. Thunø M, Macho B, Eugen-Olsen J. suPAR: the molecular crystal ball. Dis Markers. 2009; 27: 157-72.

18. Loskutoff DJ, Curriden SA, Hu G, Deng G. Regulation of cell adhesion by PAI-1. Apmis. 1999; 107: 54-61.

19. Merino P, Yepes M. Urokinase-type Plasminogen Activator Induces Neurorepair in the Ischemic Brain. J Neurol Exp Neurosci. 2018; 4: 24-9.

20. Gårdsvoll $\mathrm{H}$, Ploug $\mathrm{M}$. Mapping of the vitronectin-binding site on the urokinase receptor: involvement of a coherent receptor interface consisting of residues from both domain I and the flanking interdomain linker region. J Biol Chem. 2007; 282: 13561-72.

21. Madsen CD, Ferraris GM, Andolfo A, Cunningham O, Sidenius N. uPAR-induced cell adhesion and migration: vitronectin provides the key. J Cell Biol. 2007; 177: 927-39.

22. Deng G, Curriden SA, Wang S, Rosenberg S, Loskutoff DJ. Is plasminogen activator inhibitor-1 the molecular switch that governs urokinase receptor-mediated cell adhesion and release? J Cell Biol. 1996; 134: 1563-71.

23. Wei Y, Waltz D, Rao N, Drummond R, Rosenberg S, Chapman H. Identification of the urokinase receptor as an adhesion receptor for vitronectin. The Journal of biological chemistry. 1994; 269: 32380-8.

24. Liu M, Lin L, Høyer-Hansen G, Ploug M, Li H, Jiang L, et al. Crystal structure of the unoccupied murine urokinase-type plasminogen activator receptor (uPAR) reveals a tightly packed DII-DIII unit. FEBS Lett. 2019; 593: 1236-47.

25. Rijken DC, Lijnen HR. New insights into the molecular mechanisms of the fibrinolytic system. J Thromb Haemost. 2009; 7: 4-13.

26. Blasi F, Carmeliet P. uPAR: a versatile signalling orchestrator. Nature reviews Molecular cell biology. 2002; 3: 932-43.

27. Burgos-Panadero R, Noguera I, Cañete A, Navarro S, Noguera R. Vitronectin as a molecular player of the tumor microenvironment in neuroblastoma. BMC Cancer. 2019; 19: 479.

28. Shin K, Lechtenberg BC, Fujimoto LM, Yao Y, Bartra SS, Plano GV, et al. Structure of human Vitronectin C-terminal domain and interaction with Yersinia pestis outer membrane protein Ail. Sci Adv. 2019; 5: eaax5068.

29. Ossowski L, Clunie G, Masucci MT, Blasi F. In vivo paracrine interaction between urokinase and its receptor: effect on tumor cell invasion. J Cell Biol. 1991; 115: 1107-12

30. Persson M, Skovgaard D, Brandt-Larsen M, Christensen C, Madsen J, Nielsen $\mathrm{CH}$, et al. First-in-human uPAR PET: Imaging of Cancer Aggressiveness. Theranostics. 2015; 5: 1303-16.

31. Engelmann BE, Loft A, Kjær A, Nielsen HJ, Gerds TA, Benzon EV, et al. Positron emission tomography/computed tomography and biomarkers for early treatment response evaluation in metastatic colon cancer. Oncologist. 2014; 19: 164-72.

32. Boonstra MC, Verbeek FP, Mazar AP, Prevoo HA, Kuppen PJ, van de Velde CJ, et al. Expression of UPAR in tumor-associated stromal cells is 
associated with colorectal cancer patient prognosis: a TMA study. BMC Cancer. 2014; 14: 269.

33. Gogineni VR, Nalla AK, Gupta R, Dinh DH, Klopfenstein JD, Rao JS. Chk2-mediated G2/M cell cycle arrest maintains radiation resistance in malignant meningioma cells. Cancer Lett. 2011; 313: 64-75.

34. Wach S, Brandl M, Borchardt H, Weigelt K, Lukat S, Nolte E, et al. Exploring the MIR143-UPAR Axis for the Inhibition of Human Prostate Cancer Cells In vitro and In vivo. Mol Ther Nucleic Acids. 2019; 16: 272-83.

35. Li Y, Cozzi PJ. Targeting uPA/uPAR in prostate cancer. Cancer Treat Rev. 2007; 33: 521-7.

36. Ertongur S, Lang S, Mack B, Wosikowski K, Muehlenweg B, Gires O. Inhibition of the invasion capacity of carcinoma cells by WX-UK1, a novel synthetic inhibitor of the urokinase-type plasminogen activator system. Int J Cancer. 2004; 110: 815-24.

37. Hau AM, Leivo MZ, Gilder AS, Hu JJ, Gonias SL, Hansel DE. mTORC2 activation is regulated by the urokinase receptor (UPAR) in bladder cancer. Cell Signal. 2017; 29: 96-106.

38. Skovgaard D, Persson M, Brandt-Larsen M, Christensen C, Madsen J, Klausen TL, et al. Safety, Dosimetry, and Tumor Detection Ability of (68)Ga-NOTA-AE105: First-in-Human Study of a Novel Radioligand for uPAR PET Imaging. J Nucl Med. 2017; 58: 379-86.

39. Schlechte W, Murano G, Boyd D. Examination of the role of the urokinase receptor in human colon cancer mediated laminin degradation. Cancer Res. 1989; 49: 6064-9.

40. Del Vecchio S, Stoppelli MP, Carriero MV, Fonti R, Massa O, Li PY, et al. Human urokinase receptor concentration in malignant and benign breast tumors by in vitro quantitative autoradiography: comparison with urokinase levels. Cancer Res. 1993; 53: 3198-206.

41. Huber MC, Mall R, Braselmann H, Feuchtinger A, Molatore S, Lindner $\mathrm{K}$, et al. uPAR enhances malignant potential of triple-negative breast cancer by directly interacting with uPA and IGF1R. BMC Cancer. 2016; 16: 615 .

42. de Vries TJ, Quax PH, Denijn M, Verrijp KN, Verheijen JH, Verspaget $\mathrm{HW}$, et al. Plasminogen activators, their inhibitors, and urokinase receptor emerge in late stages of melanocytic tumor progression. Am J Pathol. 1994; 144: 70-81.

43. Mohanam S, Sawaya RE, Yamamoto M, Bruner JM, Nicholson GL, Rao JS. Proteolysis and invasiveness of brain tumors: role of urokinase-type plasminogen activator receptor. J Neurooncol. 1994; 22: 153-60.

44. Pedersen $\mathrm{H}$, Brünner N, Francis D, Osterlind K, Rønne E, Hansen $\mathrm{HH}$, et al. Prognostic impact of urokinase, urokinase receptor, and type 1 plasminogen activator inhibitor in squamous and large cell lung cancer tissue. Cancer Res. 1994; 54: 4671-5.

45. Wagner SN, Atkinson MJ, Thanner S, Wagner C, Schmitt M, Wilhelm O, et al. Modulation of urokinase and urokinase receptor gene expression in human renal cell carcinoma. Am J Pathol. 1995; 147: 183-92.

46. Morita Y, Hayashi Y, Wang Y, Kanamaru T, Suzuki S, Kawasaki K, et al. Expression of urokinase-type plasminogen activator receptor in hepatocellular carcinoma. Hepatology. 1997; 25: 856-61.

47. Dubuisson L, Monvoisin A, Nielsen BS, Le Bail B, Bioulac-Sage P, Rosenbaum J. Expression and cellular localization of the urokinase-type plasminogen activator and its receptor in human hepatocellular carcinoma. J Pathol. 2000; 190: 190-5.

48. Yonemura Y, Nojima N, Kawamura T, Ajisaka H, Taniguchi K, Fujimura $\mathrm{T}$, et al. Correlation between expression of urokinase-type plasminogen activator receptor and metastasis in gastric carcinoma. Oncol Rep. 1997; 4: 1229-34.

49. Park JS, Park JH, Khoi PN, Joo YE, Jung YD. MSP-induced RON activation upregulates UPAR expression and cell invasiveness via MAPK, AP-1 and NF-kB signals in gastric cancer cells. Carcinogenesis. 2011; 32: 175-81.

50. Sier CF, Stephens R, Bizik J, Mariani A, Bassan M, Pedersen N, et al. The level of urokinase-type plasminogen activator receptor is increased in serum of ovarian cancer patients. Cancer Res. 1998; 58: 1843-9.

51. Minopoli M, Botti G, Gigantino V, Ragone C, Sarno S, Motti ML, et al. Targeting the Formyl Peptide Receptor type 1 to prevent the adhesion of ovarian cancer cells onto mesothelium and subsequent invasion. J Exp Clin Cancer Res. 2019; 38: 459.

52. Boonstra MC, Van Driel P, Keereweer S, Prevoo H, Stammes MA, Baart VM, et al. Preclinical uPAR-targeted multimodal imaging of locoregional oral cancer. Oral Oncol. 2017; 66: 1-8.

53. Jing J, Zheng S, Han C, Du L, Guo Y, Wang P. Evaluating the value of UPAR of serum and tissue on patients with cervical cancer. J Clin Lab Anal. 2012; 26: 16-21.

54. Loosen SH, Tacke F, Püthe N, Binneboesel M, Wiltberger G, Alizai PH, et al. High baseline soluble urokinase plasminogen activator receptor (suPAR) serum levels indicate adverse outcome after resection of pancreatic adenocarcinoma. Carcinogenesis. 2019; 40: 947-55.
55. Degryse B, Britto M, Shan CX, Wallace RG, Rochfort KD, Cummins PM, et al. Moesin and merlin regulate urokinase receptor-dependent endothelial cell migration, adhesion and angiogenesis. Int J Biochem Cell Biol. 2017; 88: 14-22.

56. Li D, Liu S, Shan H, Conti P, Li Z. Urokinase plasminogen activator receptor ( $\mathrm{UPAR}$ ) targeted nuclear imaging and radionuclide therapy. Theranostics. 2013; 3: 507-15.

57. Keer HN, Gaylis FD, Kozlowski JM, Kwaan HC, Bauer KD, Sinha AA, et al. Heterogeneity in plasminogen activator (PA) levels in human prostate cancer cell lines: increased PA activity correlates with biologically aggressive behavior. Prostate. 1991; 18: 201-14.

58. Dass K, Ahmad A, Azmi AS, Sarkar SH, Sarkar FH. Evolving role of uPA/uPAR system in human cancers. Cancer Treat Rev. 2008; 34: 122-36.

59. Wang $\mathrm{K}$, Xing ZH, Jiang QW, Yang Y, Huang JR, Yuan ML, et al. Targeting uPAR by CRISPR/Cas9 System Attenuates Cancer Malignancy and Multidrug Resistance. Frontiers in oncology. 2019; 9: 80.

60. Ahn SB, Mohamedali A, Pascovici D, Adhikari S, Sharma S, Nice EC, et al. Proteomics Reveals Cell-Surface Urokinase Plasminogen Activator Receptor Expression Impacts Most Hallmarks of Cancer. Proteomics. 2019; 19: e1900026.

61. Sidaway P. Bladder cancer: UPAR expression indicates worse prognosis of urothelial carcinoma. Nat Rev Urol. 2015; 12: 120.

62. Rolff HC, Christensen IJ, Svendsen LB, Wilhelmsen M, Lund IK, Thurison $\mathrm{T}$, et al. The concentration of the cleaved suPAR forms in preand postoperative plasma samples improves the prediction of survival in colorectal cancer: A nationwide multicenter validation and discovery study. J Surg Oncol. 2019; 120: 1404-11.

63. Kita Y, Fukagawa T, Mimori K, Kosaka Y, Ishikawa K, Aikou T, et al. Expression of UPAR mRNA in peripheral blood is a favourite marker for metastasis in gastric cancer cases. Br J Cancer. 2009; 100: 153-9.

64. Semina EV, Rubina KA, Shmakova AA, Rysenkova KD, Klimovich PS, Aleksanrushkina NA, et al. Downregulation of uPAR promotes urokinase translocation into the nucleus and epithelial to mesenchymal transition in neuroblastoma. J Cell Physiol. 2020; 235: 6268-86.

65. Gao X, Guo Q, Wang S, Gao C, Chen J, Zhang L, et al. Silencing of uPAR via RNA interference inhibits invasion and migration of oral tongue squamous cell carcinoma. Oncol Lett. 2018; 16: 3983-91.

66. D'Alessio S, Blasi F. The urokinase receptor as an entertainer of signal transduction. Front Biosci (Landmark Ed). 2009; 14: 4575-87.

67. Aguirre Ghiso JA. Inhibition of FAK signaling activated by urokinase receptor induces dormancy in human carcinoma cells in vivo. Oncogene. 2002; 21: 2513-24.

68. Zhang F, Tom CC, Kugler MC, Ching TT, Kreidberg JA, Wei Y, et al. Distinct ligand binding sites in integrin alpha3beta1 regulate matrix adhesion and cell-cell contact. The Journal of cell biology. 2003; 163: 177-88.

69. Liu D, Aguirre Ghiso J, Estrada Y, Ossowski L. EGFR is a transducer of the urokinase receptor initiated signal that is required for in vivo growth of a human carcinoma. Cancer cell. 2002; 1: 445-57.

70. Mazzieri R, D'Alessio S, Kenmoe RK, Ossowski L, Blasi F. An uncleavable UPAR mutant allows dissection of signaling pathways in uPA-dependent cell migration. Molecular biology of the cell. 2006; 17: 367-78.

71. Eden G, Archinti M, Arnaudova R, Andreotti G, Motta A, Furlan F, et al D2A sequence of the urokinase receptor induces cell growth through av $\beta 3$ integrin and EGFR. Cellular and molecular life sciences : CMLS. 2018; 75: 1889-907.

72. Guo H, Wang F, Diao Y, Zhang Z, Chen Q, Qian CN, et al. Knockdown of Notch1 inhibits nasopharyngeal carcinoma cell growth and metastasis via downregulation of CCL2, CXCL16, and uPA. Mol Carcinog. 2019; 58: 1886-96.

73. Liu X, Lan Y, Zhang D, Wang K, Wang Y, Hua ZC. SPRY1 promotes the degradation of uPAR and inhibits uPAR-mediated cell adhesion and proliferation. Am J Cancer Res. 2014; 4: 683-97.

74. Nowicki TS, Zhao H, Darzynkiewicz Z, Moscatello A, Shin E, Schantz S, et al. Downregulation of UPAR inhibits migration, invasion, proliferation, FAK/PI3K/Akt signaling and induces senescence in papillary thyroid carcinoma cells. Cell cycle (Georgetown, Tex). 2011; 10: $100-7$.

75. Xue A, Xue M, Jackson C, Smith RC. Suppression of urokinase plasminogen activator receptor inhibits proliferation and migration of pancreatic adenocarcinoma cells via regulation of ERK/p38 signaling. The international journal of biochemistry \& cell biology. 2009; 41: 1731-8.

76. Hamurcu Z, Delibaşı N, Geçene S, Şener EF, Dönmez-Altuntaş H, Özkul $\mathrm{Y}$, et al. Targeting LC3 and Beclin-1 autophagy genes suppresses proliferation, survival, migration and invasion by inhibition of Cyclin-D1 and uPAR/Integrin $\beta 1$ / Src signaling in triple negative breast cancer cells. J Cancer Res Clin Oncol. 2018; 144: 415-30. 
77. Steelman LS, Chappell WH, Abrams SL, Kempf RC, Long J, Laidler P, et al. Roles of the Raf/MEK/ERK and PI3K/PTEN/Akt/mTOR pathways in controlling growth and sensitivity to therapy-implications for cancer and aging. Aging. 2011; 3: 192-222.

78. Grismayer B, Sato S, Kopitz C, Ries C, Soelch S, Schmitt M, et al. Overexpression of the urokinase receptor splice variant uPAR-del4/5 in breast cancer cells affects cell adhesion and invasion in a dose-dependent manner and modulates transcription of tumor-associated genes. Biological chemistry. 2012; 393: 1449-55.

79. May AE, Schmidt R, Kanse SM, Chavakis T, Stephens RW, Schömig A, et al. Urokinase receptor surface expression regulates monocyte adhesion in acute myocardial infarction. Blood. 2002; 100: 3611-7.

80. Ferraris GM, Schulte C, Buttiglione V, De Lorenzi V, Piontini A, Galluzzi $\mathrm{M}$, et al. The interaction between $\mathrm{UPAR}$ and vitronectin triggers ligand-independent adhesion signalling by integrins. Embo j. 2014; 33: 2458-72.

81. Nishii K, Nakaseko C, Jiang M, Shimizu N, Takeuchi M, Schneider WJ, et al. The soluble form of LR11 protein is a regulator of hypoxia-induced, urokinase-type plasminogen activator receptor (UPAR)-mediated adhesion of immature hematological cells. J Biol Chem. 2013; 288: 11877-86

82. Paysant J, Vasse M, Soria J, Lenormand B, Pourtau J, Vannier JP, et al. Regulation of the uPAR/uPA system expressed on monocytes by the deactivating cytokines, IL-4, IL-10 and IL-13: consequences on cell adhesion to vitronectin and fibrinogen. Br J Haematol. 1998; 100: 45-51.

83. Rao Malla R, Gopinath S, Alapati K, Gorantla B, Gondi CS, Rao JS. Knockdown of cathepsin B and UPAR inhibits CD151 and a3 $\beta 1$ integrin-mediated cell adhesion and invasion in glioma. Mol Carcinog. 2013; 52: 777-90.

84. Annis MG, Ouellet V, Rennhack JP, L'Esperance S, Rancourt C, Mes-Masson AM, et al. Integrin-uPAR signaling leads to FRA-1 phosphorylation and enhanced breast cancer invasion. Breast Cancer Res. 2018; 20: 9 .

85. Principe M, Borgoni S, Cascione M, Chattaragada MS, Ferri-Borgogno S, Capello M, et al. Alpha-enolase (ENO1) controls alpha v/ beta 3 integrin expression and regulates pancreatic cancer adhesion, invasion, and metastasis. J Hematol Oncol. 2017; 10: 16.

86. Sidenius N, Blasi F. The urokinase plasminogen activator system in cancer: recent advances and implication for prognosis and therapy. Cancer Metastasis Rev. 2003; 22: 205-22.

87. Tang $\mathrm{L}, \mathrm{Han} X$. The urokinase plasminogen activator system in breast cancer invasion and metastasis. Biomedicine \& pharmacotherapy $=$ Biomedecine \& pharmacotherapie. 2013; 67: 179-82.

88. Danø K, Behrendt N, Høyer-Hansen G, Johnsen M, Lund LR, Ploug M, et al. Plasminogen activation and cancer. Thromb Haemost. 2005; 93: 676-81.

89. Hillig T, Engelholm LH, Ingvarsen S, Madsen DH, Gårdsvoll H, Larsen $\mathrm{JK}$, et al. A composite role of vitronectin and urokinase in the modulation of cell morphology upon expression of the urokinase receptor. J Biol Chem. 2008; 283: 15217-23.

90. Prager GW, Breuss JM, Steurer S, Mihaly J, Binder BR. Vascular endothelial growth factor (VEGF) induces rapid prourokinase (pro-uPA) activation on the surface of endothelial cells. Blood. 2004; 103: 955-62.

91. Hamidi H, Ivaska J. Every step of the way: integrins in cancer progression and metastasis. Nature reviews Cancer. 2018; 18: 533-48.

92. Wei Y, Lukashev M, Simon DI, Bodary SC, Rosenberg S, Doyle MV, et al. Regulation of integrin function by the urokinase receptor. Science (New York, NY). 1996; 273: 1551-5.

93. Wei C, Möller CC, Altintas MM, Li J, Schwarz K, Zacchigna S, et al. Modification of kidney barrier function by the urokinase receptor. Nature medicine. 2008; 14: 55-63.

94. Masi I, Caprara V, Bagnato A, Rosanò L. Tumor Cellular and Microenvironmental Cues Controlling Invadopodia Formation. Front Cell Dev Biol. 2020; 8: 584181.

95. Smith HW, Marra P, Marshall CJ. uPAR promotes formation of the p130Cas-Crk complex to activate Rac through DOCK180. The Journal of cell biology. 2008; 182: 777-90.

96. Kjøller L, Hall A. Rac mediates cytoskeletal rearrangements and increased cell motility induced by urokinase-type plasminogen activator receptor binding to vitronectin. The Journal of cell biology. 2001; 152: 1145-57.

97. Yeh HW, Hsu EC, Lee SS, Lang YD, Lin YC, Chang CY, et al. PSPC1 mediates TGF- $\beta 1$ autocrine signalling and Smad2/3 target switching to promote EMT, stemness and metastasis. Nat Cell Biol. 2018; 20: 479-91.

98. Wilkes MC, Mitchell H, Penheiter SG, Doré JJ, Suzuki K, Edens M, et al. Transforming growth factor-beta activation of phosphatidylinositol 3-kinase is independent of Smad2 and Smad3 and regulates fibroblast responses via p21-activated kinase-2. Cancer research. 2005; 65: 10431-40.
99. Magnussen SN, Hadler-Olsen E, Costea DE, Berg E, Jacobsen CC, Mortensen B, et al. Cleavage of the urokinase receptor (UPAR) on oral cancer cells: regulation by transforming growth factor - $\beta 1$ (TGF- $\beta 1$ ) and potential effects on migration and invasion. BMC cancer. 2017; 17: 350.

100. Gogineni VR, Gupta R, Nalla AK, Velpula KK, Rao JS. uPAR and cathepsin B shRNA impedes TGF- $\beta 1$-driven proliferation and invasion of meningioma cells in a XIAP-dependent pathway. Cell Death Dis. 2012; 3: e439.

101. Jaiswal RK, Yadava PK. TGF- $\beta$-mediated regulation of plasminogen activators is human telomerase reverse transcriptase dependent in cancer cells. Biofactors. 2019; 45: 803-17.

102. Heldin $\mathrm{CH}$, Vanlandewijck M, Moustakas A. Regulation of EMT by TGF $\beta$ in cancer. FEBS Lett. 2012; 586: 1959-70.

103. Santibanez JF, Obradović H, Kukolj T, Krstić J. Transforming growth factor- $\beta$, matrix metalloproteinases, and urokinase-type plasminogen activator interaction in the cancer epithelial to mesenchymal transition. Dev Dyn. 2018; 247: 382-95.

104. Orlichenko LS, Radisky DC. Matrix metalloproteinases stimulate epithelial-mesenchymal transition during tumor development. Clinical \& experimental metastasis. 2008; 25: 593-600.

105. Teraoka H, Sawada T, Yamashita Y, Nakata B, Ohira M, Ishikawa T, et al. TGF-beta1 promotes liver metastasis of pancreatic cancer by modulating the capacity of cellular invasion. International journal of oncology. 2001; 19: 709-15.

106. Yue J, Sun B, Liu G, Mulder KM. Requirement of TGF-beta receptor-dependent activation of c-Jun N-terminal kinases (JNKs)/stress-activated protein kinases (Sapks) for TGF-beta up-regulation of the urokinase-type plasminogen activator receptor. Journal of cellular physiology. 2004; 199: 284-92.

107. Laurenzana A, Biagioni A, Bianchini F, Peppicelli S, Chillà A, Margheri $\mathrm{F}$, et al. Inhibition of uPAR-TGF $\beta$ crosstalk blocks MSC-dependent EMT in melanoma cells. J Mol Med (Berl). 2015; 93: 783-94.

108. Huang C, Xie D, Cui J, Li Q, Gao Y, Xie K. FOXM1c promotes pancreatic cancer epithelial-to-mesenchymal transition and metastasis via upregulation of expression of the urokinase plasminogen activator system. Clin Cancer Res. 2014; 20: 1477-88.

109. Devulapally R, Sekar NM, Sekar TV, Foygel K, Massoud TF, Willmann JK, et al. Polymer nanoparticles mediated codelivery of antimiR-10b and antimiR-21 for achieving triple negative breast cancer therapy. ACS nano. 2015; 9: 2290-302

110. Tupone MG, D'Aguanno S, Di Martile M, Valentini E, Desideri M, Trisciuoglio D, et al. microRNA-378a-5p iS a novel positive regulator of melanoma progression. Oncogenesis. 2020; 9: 22.

111. Yachi K, Tsuda M, Kohsaka S, Wang L, Oda Y, Tanikawa S, et al. miR-23a promotes invasion of glioblastoma via HOXD10-regulated glial-mesenchymal transition. Signal Transduct Target Ther. 2018; 3: 33.

112. Gu C, Zhang M, Sun W, Dong C. Upregulation of miR-324-5p Inhibits Proliferation and Invasion of Colorectal Cancer Cells by Targeting ELAVL1. Oncol Res. 2019; 27: 515-24.

113. Iwamoto N, Vettori S, Maurer B, Brock M, Pachera E, Jüngel A, et al. Downregulation of miR-193b in systemic sclerosis regulates the proliferative vasculopathy by urokinase-type plasminogen activator expression. Annals of the rheumatic diseases. 2016; 75: 303-10.

114. Yan X, Chen X, Liang H, Deng T, Chen W, Zhang S, et al. miR-143 and miR-145 synergistically regulate ERBB3 to suppress cell proliferation and invasion in breast cancer. Molecular cancer. 2014; 13: 220

115. Tang X, Hou Y, Yang G, Wang X, Tang S, Du YE, et al. Stromal miR-200s contribute to breast cancer cell invasion through CAF activation and ECM remodeling. Cell death and differentiation. 2016; 23: 132-45.

116. Carriero MV, Bifulco K, Ingangi V, Costantini S, Botti G, Ragone C, et al. Retro-inverso Urokinase Receptor Antagonists for the Treatment of Metastatic Sarcomas. Sci Rep. 2017; 7: 1312.

117. Bifulco K, Longanesi-Cattani I, Franco P, Pavone V, Mugione P, Di Carluccio G, et al. Single amino acid substitutions in the chemotactic sequence of urokinase receptor modulate cell migration and invasion. PLoS One. 2012; 7: e44806.

118. Mauro CD, Pesapane A, Formisano L, Rosa R, D'Amato V, Ciciola P, et al. Urokinase-type plasminogen activator receptor (uPAR) expression enhances invasion and metastasis in RAS mutated tumors. Sci Rep. 2017; 7: 9388.

119. Lian S, Xia Y, Ung TT, Khoi PN, Yoon HJ, Lee SG, et al. Prostaglandin $\mathrm{E}(2)$ stimulates urokinase-type plasminogen activator receptor via EP2 receptor-dependent signaling pathways in human AGS gastric cancer cells. Mol Carcinog. 2017; 56: 664-80.

120. Yang QX, Zhong S, He L, Jia XJ, Tang H, Cheng ST, et al. PBK overexpression promotes metastasis of hepatocellular carcinoma via activating ETV4-uPAR signaling pathway. Cancer Lett. 2019; 452: 90-102.

121. Anichini E, Zamperini A, Chevanne M, Caldini R, Pucci M, Fibbi G, et al. Interaction of urokinase-type plasminogen activator with its receptor 
rapidly induces activation of glucose transporters. Biochemistry. 1997; 36: 3076-83.

122. Nishi H, Sasaki T, Nagamitsu $Y$, Terauchi F, Nagai T, Nagao T, et al. Hypoxia inducible factor-1 mediates upregulation of urokinase-type plasminogen activator receptor gene transcription during hypoxia in cervical cancer cells. Oncol Rep. 2016; 35: 992-8.

123. Graham CH, Forsdike J, Fitzgerald CJ, Macdonald-Goodfellow S. Hypoxia-mediated stimulation of carcinoma cell invasiveness via upregulation of urokinase receptor expression. International journal of cancer. 1999; 80: 617-23.

124. Rofstad EK, Rasmussen H, Galappathi K, Mathiesen B, Nilsen K, Graff BA. Hypoxia promotes lymph node metastasis in human melanoma xenografts by up-regulating the urokinase-type plasminogen activator receptor. Cancer Res. 2002; 62: 1847-53.

125. Park EJ, Lee YM, Oh TI, Kim BM, Lim BO, Lim JH. Vanillin Suppresses Cell Motility by Inhibiting STAT3-Mediated HIF-1a mRNA Expression in Malignant Melanoma Cells. Int J Mol Sci. 2017; 18.

126. Ma X, Li C, Sun L, Huang D, Li T, He X, et al. Lin28/let-7 axis regulates aerobic glycolysis and cancer progression via PDK1. Nat Commun. 2014; 5: 5212.

127. Yang S, Pascual-Guiral S, Ponce R, Giménez-Llort L, Baltrons MA, Arancio $\mathrm{O}$, et al. Reducing the Levels of Akt Activation by PDK1 Knock-in Mutation Protects Neuronal Cultures against Synthetic Amyloid-Beta Peptides. Front Aging Neurosci. 2017; 9: 435.

128. Zhou J, Kwak KJ, Wu Z, Yang D, Li J, Chang M, et al. PLAUR Confers Resistance to Gefitinib Through EGFR/P-AKT/Survivin Signaling Pathway. Cell Physiol Biochem. 2018; 47: 1909-24.

129. Al-Hassan NN, Behzadian A, Caldwell R, Ivanova VS, Syed V, Motamed $\mathrm{K}$, et al. Differential roles of UPAR in peritoneal ovarian carcinomatosis. Neoplasia. 2012; 14: 259-70.

130. Hao W, Friedman A. Serum uPAR as Biomarker in Breast Cancer Recurrence: A Mathematical Model. PLoS One. 2016; 11: e0153508.

131. Odekon LE, Blasi F, Rifkin DB. Requirement for receptor-bound urokinase in plasmin-dependent cellular conversion of latent TGF-beta to TGF-beta. J Cell Physiol. 1994; 158: 398-407.

132. Chen J, Ding ZY, Li S, Liu S, Xiao C, Li Z, et al. Targeting transforming growth factor- $\beta$ signaling for enhanced cancer chemotherapy. Theranostics. 2021; 11: 1345-63.

133. Hu J, Jo M, Eastman BM, Gilder AS, Bui JD, Gonias SL. uPAR induces expression of transforming growth factor $\beta$ and interleukin- 4 in cancer cells to promote tumor-permissive conditioning of macrophages. Am J Pathol. 2014; 184: 3384-93.

134. Hu J, Jo M, Cavenee WK, Furnari F, VandenBerg SR, Gonias SL. Crosstalk between the urokinase-type plasminogen activator receptor and EGF receptor variant III supports survival and growth of glioblastoma cells. Proc Natl Acad Sci U S A. 2011; 108: 15984-9.

135. Laurenzana A, Fibbi G, Margheri F, Biagioni A, Luciani C, Del Rosso M, et al. Endothelial Progenitor Cells in Sprouting Angiogenesis: Proteases Pave the Way. Curr Mol Med. 2015; 15: 606-20.

136. Li Santi A, Napolitano F, Montuori N, Ragno P. The Urokinase Receptor: A Multifunctional Receptor in Cancer Cell Biology. Therapeutic Implications. Int J Mol Sci. 2021; 22.

137. Fibbi G, Caldini R, Chevanne M, Pucci M, Schiavone N, Morbidelli L, et al. Urokinase-dependent angiogenesis in vitro and diacylglycerol production are blocked by antisense oligonucleotides against the urokinase receptor. Lab Invest. 1998; 78: 1109-19.

138. Herkenne S, Paques C, Nivelles O, Lion M, Bajou K, Pollenus T, et al. The interaction of UPAR with VEGFR2 promotes VEGF-induced angiogenesis. Sci Signal. 2015; 8: ra117.

139. Alexander RA, Prager GW, Mihaly-Bison J, Uhrin P, Sunzenauer S, Binder BR, et al. VEGF-induced endothelial cell migration requires urokinase receptor (uPAR)-dependent integrin redistribution. Cardiovasc Res. 2012; 94: 125-35.

140. Poettler M, Unseld M, Mihaly-Bison J, Uhrin P, Koban F, Binder BR, et al. The urokinase receptor (CD87) represents a central mediator of growth factor-induced endothelial cell migration. Thromb Haemost. 2012; 108: 357-66.

141. Chillà A, Margheri F, Biagioni A, Del Rosso M, Fibbi G, Laurenzana A. Mature and progenitor endothelial cells perform angiogenesis also under protease inhibition: the amoeboid angiogenesis. J Exp Clin Cancer Res. 2018; 37: 74.

142. Margheri F, Papucci L, Schiavone N, D'Agostino R, Trigari S, Serratì S, et al. Differential uPAR recruitment in caveolar-lipid rafts by GM1 and GM3 gangliosides regulates endothelial progenitor cells angiogenesis. J Cell Mol Med. 2015; 19: 113-23.

143. Margheri F, Chillà A, Laurenzana A, Serratì S, Mazzanti B, Saccardi R, et al. Endothelial progenitor cell-dependent angiogenesis requires localization of the full-length form of UPAR in caveolae. Blood. 2011; 118: 3743-55.
144. D'Alessio S, Fibbi G, Cinelli M, Guiducci S, Del Rosso A, Margheri F, et al. Matrix metalloproteinase 12-dependent cleavage of urokinase receptor in systemic sclerosis microvascular endothelial cells results in impaired angiogenesis. Arthritis Rheum. 2004; 50: 3275-85.

145. Andreucci E, Margheri F, Peppicelli S, Bianchini F, Ruzzolini J, Laurenzana A, et al. Glycolysis-derived acidic microenvironment as a driver of endothelial dysfunction in systemic sclerosis. Rheumatology (Oxford). 2021.

146. Laurenzana A, Biagioni A, D'Alessio S, Bianchini F, Chillà A, Margheri F, et al. Melanoma cell therapy: Endothelial progenitor cells as shuttle of the MMP12 uPAR-degrading enzyme. Oncotarget. 2014; 5: 3711-27.

147. Serratì S, Margheri F, Pucci M, Cantelmo AR, Cammarota R, Dotor J, et al. TGFbeta1 antagonistic peptides inhibit TGFbeta1-dependent angiogenesis. Biochem Pharmacol. 2009; 77: 813-25.

148. Margheri F, Schiavone N, Papucci L, Magnelli L, Serratì S, Chillà A, et al. GDF5 regulates TGFß-dependent angiogenesis in breast carcinoma MCF-7 cells: in vitro and in vivo control by anti-TGFß peptides. PLoS One. 2012; 7: e50342.

149. Biagioni A, Laurenzana A, Menicacci B, Peppicelli S, Andreucci E, Bianchini $\mathrm{F}$, et al. uPAR-expressing melanoma exosomes promote angiogenesis by VE-Cadherin, EGFR and uPAR overexpression and rise of ERK1,2 signaling in endothelial cells. Cell Mol Life Sci. 2021; 78: 3057-72.

150. Record M, Carayon K, Poirot M, Silvente-Poirot S. Exosomes as new vesicular lipid transporters involved in cell-cell communication and various pathophysiologies. Biochim Biophys Acta. 2014; 1841: 108-20.

151. Unseld M, Chilla A, Pausz C, Mawas R, Breuss J, Zielinski C, et al. PTEN expression in endothelial cells is down-regulated by uPAR to promote angiogenesis. Thromb Haemost. 2015; 114: 379-89.

152. Manetti M, Rosa I, Milia AF, Guiducci S, Carmeliet P, Ibba-Manneschi L, et al. Inactivation of urokinase-type plasminogen activator receptor (uPAR) gene induces dermal and pulmonary fibrosis and peripheral microvasculopathy in mice: a new model of experimental scleroderma? Ann Rheum Dis. 2014; 73: 1700-9.

153. Zhang J, Sud S, Mizutani K, Gyetko MR, Pienta KJ. Activation of urokinase plasminogen activator and its receptor axis is essential for macrophage infiltration in a prostate cancer mouse model. Neoplasia. 2011; 13: 23-30.

154. van Hagen P, Hulshof MC, van Lanschot JJ, Steyerberg EW, van Berge Henegouwen MI, Wijnhoven BP, et al. Preoperative chemoradiotherapy for esophageal or junctional cancer. N Engl J Med. 2012; 366: 2074-84.

155. Semenkovich TR, Meyers BF. Surveillance versus esophagectomy in esophageal cancer patients with a clinical complete response after induction chemoradiation. Ann Transl Med. 2018; 6: 81.

156. Chen X, Wei H, Qian D, Wang Y, Guan Y, Er P, et al. Predictive value of EGF and UPAR for chemoradiotherapy response and survival in patients with esophageal squamous cell carcinoma. Ann Transl Med. 2020; 8: 1152.

157. Wu L, Blum W, Zhu CQ, Yun Z, Pecze L, Kohno M, et al. Putative cancer stem cells may be the key target to inhibit cancer cell repopulation between the intervals of chemoradiation in murine mesothelioma. BMC Cancer. 2018; 18: 471

158. Ostheimer C, Evers C, Bache M, Reese T, Vordermark D. Prognostic implications of the co-detection of the urokinase plasminogen activator system and osteopontin in patients with non-small-cell lung cancer undergoing radiotherapy and correlation with gross tumor volume. Strahlenther Onkol. 2018; 194: 539-51.

159. Hohensinner PJ, Baumgartner J, Kral-Pointner JB, Uhrin P, Ebenbauer B, Thaler B, et al. PAI-1 (Plasminogen Activator Inhibitor-1) Expression Renders Alternatively Activated Human Macrophages Proteolytically Quiescent. Arterioscler Thromb Vasc Biol. 2017; 37: 1913-22.

160. Rasch MG, Lund IK, Almasi CE, Hoyer-Hansen G. Intact and cleaved uPAR forms: diagnostic and prognostic value in cancer. Front Biosci. 2008; 13: 6752-62.

161. Li H, Chen C. Quercetin Has Antimetastatic Effects on Gastric Cancer Cells via the Interruption of uPA/uPAR Function by Modulating NF-kb, PKC-ס, ERK1/2, and AMPKa. Integr Cancer Ther. 2018; 17: 511-23.

162. Lee KS, Nam GS, Baek J, Kim S, Nam KS. Inhibition of TPA-induced metastatic potential by morin hydrate in MCF-7 human breast cancer cells via the Akt/GSK-3 $\beta$ /c-Fos signaling pathway. Int J Oncol. 2020; 56: 630-40.

163. Xia Y, Yuan M, Li S, Thuan UT, Nguyen TT, Kang TW, et al. Apigenin Suppresses the IL-1 $\beta$-Induced Expression of the Urokinase-Type Plasminogen Activator Receptor by Inhibiting MAPK-Mediated AP-1 and NF-kB Signaling in Human Bladder Cancer T24 Cells. J Agric Food Chem. 2018; 66: 7663-73.

164. Minopoli M, Polo A, Ragone C, Ingangi V, Ciliberto G, Pessi A, et al. Structure-function relationship of an Urokinase Receptor-derived 
peptide which inhibits the Formyl Peptide Receptor type 1 activity. Sci Rep. 2019; 9: 12169.

165. Ragone C, Minopoli M, Ingangi V, Botti G, Fratangelo F, Pessi A, et al. Targeting the cross-talk between Urokinase receptor and Formyl peptide receptor type 1 to prevent invasion and trans-endothelial migration of melanoma cells. J Exp Clin Cancer Res. 2017; 36: 180.

166. Harel ET, Drake PM, Barfield RM, Lui I, Farr-Jones S, Van't Veer L, et al. Antibody-Drug Conjugates Targeting the Urokinase Receptor (uPAR) as a Possible Treatment of Aggressive Breast Cancer. Antibodies (Basel). $2019 ; 8$.

167. Amor C, Feucht J, Leibold J, Ho YJ, Zhu C, Alonso-Curbelo D, et al. Senolytic CAR T cells reverse senescence-associated pathologies. Nature. 2020; 583: 127-32.

168. Sadelain M, Rivière I, Riddell S. Therapeutic T cell engineering. Nature. 2017; 545: 423-31.

169. Herranz N, Gil J. Mechanisms and functions of cellular senescence. J Clin Invest. 2018; 128: 1238-46.

170. Childs BG, Baker DJ, Wijshake T, Conover CA, Campisi J, van Deursen JM. Senescent intimal foam cells are deleterious at all stages of atherosclerosis. Science. 2016; 354: 472-7.

171. Hong M, Clubb JD, Chen YY. Engineering CAR-T Cells for Next-Generation Cancer Therapy. Cancer Cell. 2020; 38: 473-88.

172. Li JH, Chen YY. A Fresh Approach to Targeting Aging Cells: CAR-T Cells Enhance Senolytic Specificity. Cell Stem Cell. 2020; 27: 192-4.

173. Enocsson H, Lukic T, Ziegelasch M, Kastbom A. Serum levels of the soluble urokinase plasminogen activator receptor (suPAR) correlates with disease activity in early rheumatoid arthritis and reflects joint damage over time. Transl Res. 2021.

174. Wang L, Yang R, Zhao L, Zhang X, Xu T, Cui M. Basing on uPAR-binding fragment to design chimeric antigen receptors triggers antitumor efficacy against uPAR expressing ovarian cancer cells. Biomed Pharmacother. 2019; 117: 109173.

175. Lund IK, Jögi A, Rønø B, Rasch MG, Lund LR, Almholt K, et al. Antibody-mediated targeting of the urokinase-type plasminogen activator proteolytic function neutralizes fibrinolysis in vivo. J Biol Chem. 2008; 283: 32506-15.

176. Zhou HM, Nichols A, Meda P, Vassalli JD. Urokinase-type plasminogen activator and its receptor synergize to promote pathogenic proteolysis. Embo j. 2000; 19: 4817-26.

177. Mahmood N, Arakelian A, Khan HA, Tanvir I, Mazar AP, Rabbani SA. uPAR antibody (huATN-658) and Zometa reduce breast cancer growth and skeletal lesions. Bone Res. 2020; 8: 18.

178. Deng M, Gui X, Kim J, Xie L, Chen W, Li Z, et al. LILRB4 signalling in leukaemia cells mediates $\mathrm{T}$ cell suppression and tumour infiltration. Nature. 2018; 562: 605-9.

179. Tanaudommongkon I, Tanaudommongkon A, Prathipati P, Nguyen JT, Keller ET, Dong X. Curcumin Nanoparticles and Their Cytotoxicity in Docetaxel-

Resistant Castration-Resistant Prostate Cancer Cells. Biomedicines. 2020; 8.

180. Wang W, Zhou J, Zhao L, Chen S. Combination of SL327 and Sunitinib Malate leads to an additive anti-cancer effect in doxorubicin resistant thyroid carcinoma cells. Biomed Pharmacother. 2017; 88: 985-90.

181. Yin T, Xin H, Yu J, Teng F. The role of exosomes in tumour immunity under radiotherapy: eliciting abscopal effects? Biomark Res. 2021; 9: 22.

182. Uzawa K, Amelio AL, Kasamatsu A, Saito T, Kita A, Fukamachi M, et al. Resveratrol Targets Urokinase-Type Plasminogen Activator Receptor Expression to Overcome Cetuximab-Resistance in Oral Squamous Cell Carcinoma. Sci Rep. 2019; 9: 12179.

183. Laurenzana A, Margheri F, Biagioni A, Chillà A, Pimpinelli N, Ruzzolini $\mathrm{J}$, et al. EGFR/uPAR interaction as druggable target to overcome vemurafenib acquired resistance in melanoma cells. EBioMedicine. 2019; 39: 194-206.

184. Wang Y, Wang W, Wu X, Li C, Huang Y, Zhou H, et al. Resveratrol Sensitizes Colorectal Cancer Cells to Cetuximab by Connexin 43 Upregulation-Induced Akt Inhibition. Front Oncol. 2020; 10: 383.

185. Biagioni A, Laurenzana A, Chillà A, Del Rosso M, Andreucci E, Poteti M, et al. uPAR Knockout Results in a Deep Glycolytic and OXPHOS Reprogramming in Melanoma and Colon Carcinoma Cell Lines. Cells. 2020; 9 .

186. Mazar AP. Urokinase plasminogen activator receptor choreographs multiple ligand interactions: implications for tumor progression and therapy. Clin Cancer Res. 2008; 14: 5649-55.

187. Huang Y, Liu T. Step further towards targeted senolytic therapy: therapeutic potential of uPAR-CAR T cells for senescence-related diseases. Signal Transduct Target Ther. 2020; 5: 155.

188. Ali G, Zhang M, Zhao R, Jain KG, Chang J, Komatsu S, et al. Fibrinolytic niche is required for alveolar type 2 cell-mediated alveologenesis via a uPA-
A6-CD44(+)-ENaC signal cascade. Signal Transduct Target Ther. 2021; 6 : 97.

189. D'Alonzo D, De Fenza M, Pavone V. COVID-19 and pneumonia: a role for the uPA/uPAR system. Drug Discov Today. 2020; 25: 1528-34 